\title{
Leptin-Receptor-Expressing Neurons in the Dorsomedial Hypothalamus and Median Preoptic Area Regulate Sympathetic Brown Adipose Tissue Circuits
}

\author{
Yan Zhang, ${ }^{1}$ Ilan A. Kerman, ${ }^{2}$ Amanda Laque, ${ }^{1}$ Phillip Nguyen, ${ }^{1}$ Miro Faouzi, ${ }^{3}$ Gwendolyn W. Louis, ${ }^{3}$ Justin C. Jones, ${ }^{3}$ \\ Chris Rhodes, ${ }^{4}$ and Heike Münzberg ${ }^{1}$ \\ ${ }^{1}$ Pennington Biomedical Research Center, Louisiana State University System, Baton Rouge, Louisiana 70808, ${ }^{2}$ Molecular and Behavioral Neuroscience \\ Institute, University of Michigan, Ann Arbor, Michigan 48109, ${ }^{3}$ Division of Metabolism, Endocrinology, and Diabetes, Department of Medicine, University \\ of Michigan Medical School, Ann Arbor, Michigan 48109, and ${ }^{4}$ Kovler Diabetes Center, University of Chicago, Chicago, Illinois 60637
}

Brown adipose tissue (BAT) thermogenesis is critical to maintain homoeothermia and is centrally controlled via sympathetic outputs. Body temperature and BAT activity also impact energy expenditure, and obesity is commonly associated with decreased BAT capacity and sympathetic tone. Severely obese mice that lack leptin or its receptor (LepRb) show decreased BAT capacity, sympathetic tone, and body temperature and thus are unable to adapt to acute cold exposure (Trayhurn et al., 1976). LepRb-expressing neurons are found in several hypothalamic sites, including the dorsomedial hypothalamus (DMH) and median preoptic area (mPOA), both critical sites to regulate sympathetic, thermoregulatory BAT circuits. Specifically, a subpopulation in the DMH/dorsal hypothalamic area (DHA) is stimulated by fever-inducing endotoxins or cold exposure (Dimicco and Zaretsky, 2007; Morrison et al., 2008). Using the retrograde, transsynaptic tracer pseudorabies virus (PRV) injected into the BAT of mice, we identified PRV-labeled LepRb neurons in the DMH/DHA and $\mathrm{mPOA}$ (and other sites), thus indicating their involvement in the regulation of sympathetic BAT circuits. Indeed, acute cold exposure induced c-Fos (as a surrogate for neuronal activity) in DMH/DHA LepRb neurons, and a large number of mPOA LepRb neurons project to the DMH/DHA. Furthermore, DMH/DHA LepRb neurons (and a subpopulation of LepRb mPOA neurons) project and synaptically couple to rostral raphe pallidus neurons, consistent with the current understanding of BAT thermoregulatory circuits from the DMH/ DHA and mPOA (Dimicco and Zaretsky, 2007; Morrison et al., 2008). Thus, these data present strong evidence that LepRb neurons in the $\mathrm{DMH} / \mathrm{DHA}$ and mPOA mediate thermoregulatory leptin action.

\section{Introduction}

Leptin acts in the CNS to coordinate metabolism and energy balance. Deficiency of leptin or its receptor (LepRb) results in profound neuroendocrine failure, hyperphagia, and autonomic dysfunction (Ozata et al., 1999; Ahima et al., 2000; Hausberg et al., 2002). This results in severe thermogenic defects and the inability to adapt to acute cold exposure attributable to decreased brown adipose tissue

\footnotetext{
Received June 22, 2010; revised 0ct. 20, 2010; accepted Nov. 22, 2010.

This work was supported by National Institutes of Health (NIH) Grants P/F DK020572-30 and P20 RR02195 and a Young Investigator Award from the American Heart Association (AHA053298N) (H.M.), a National Alliance for Research on Schizophrenia and Depression Young Investigator Award and National Institute of Mental Health Grant 5K99MH081927-02 (I.A.K.), and NIH Grant DK055267 (C.R.). Pseudorabies virus strains were provided by Dr. L. W. Enquist (Princeton University, Princeton, $N J)$ as a service of the National (enter for Experimental Neuroanatomy with Neurotropic Viruses under National Center for Research Resources Grant P40 RR0118604 and the National Science Foundation under Agreement IBN-9876754. This work used the facilities of the Cell Biology and Bioimaging Core, supported in part by Centers of Biomedical Research Excellence (NIH Grant P20-RR021945) and Clinical Neuroscience Research Unit (NIH Grant 1P30-DK072476) center grants from NIH. Partial support was provided through the Anima Phenotyping Core supported through Nutrition Obesity Research Center Grant 1P30 DK072476 entitled "Nutritiona Programming: Environmental and Molecular Interactions" sponsored by National Institute of Diabetes and Digestive and Kidney Diseases.

Correspondence should be addressed to Dr. Heike Münzberg, Pennington Biomedical Research Center, Louisiana State University System, 6400 Perkins Road, Baton Rouge, LA 70808. E-mail: Heike.Munzberg@pbrc.edu. Dr. Y. Zhang's present address: Tianjin Medical University Eye Center, Tianjin, P.R. China 300070. DOI:10.1523/JNEUROSCI.3223-10.2011

Copyright $\odot 2011$ the authors $\quad 0270-6474 / 11 / 311873-12 \$ 15.00 / 0$
}

(BAT) function (Trayhurn et al., 1976, 1977; Himms-Hagen, 1985). However, little is known about the neuronal circuits involved in thermogenic leptin action.

Several central components that regulate sympathetic, thermogenic BAT circuits have been unraveled. The median preoptic area ( $\mathrm{mPOA}$ ) plays a key role, and a distinct set of mPOA neurons projects directly to premotor neurons in the medullary rostral raphe pallidus ( $\mathrm{rRPa}$ ) to regulate sympathetic BAT inputs (Yoshida et al., 2009). However, the dorsomedial hypothalamus $(\mathrm{DMH})$ is required to mediate $\mathrm{mPOA}$-evoked thermoregulatory responses (Dimicco and Zaretsky, 2007). Specifically, neurons bordering the $\mathrm{DMH}$ and dorsal hypothalamic area (DHA) receive inhibitory inputs from the mPOA (Nakamura et al., 2005), and systemic inflammation and cold exposure both activate DMH/DHA neurons as a result of decreased inhibitory $\mathrm{mPOA}$ inputs (Elmquist et al., 1996; Cano et al., 2003; Sarkar et al., 2007).

At least two thermoregulatory circuits originate from $\mathrm{DMH}$ neurons, a direct projection to the $\mathrm{rRPa}$ from DMH/DHA neurons (Sarkar et al., 2007; Yoshida et al., 2009) and projections to the paraventricular nucleus (PVN) possibly regulating neuroendocrine and/or preautonomic outputs (ter Horst and Luiten, 1986; Thompson et al., 1996; Zaretskaia et al., 2008; Hunt et al., 2010). 
Leptin target neurons that express LepRb are found in several hypothalamic and extra-hypothalamic sites, including a large population in the DMH as well as in the mPOA (Myers et al., 2009). Thus, we hypothesized that at least a subpopulation of these LepRb neurons represent known thermoregulatory neurons that project to the rRPa or PVN as described above.

Here, we provide clear evidence that LepRb neurons in the DMH/DHA and mPOA (and other sites) are involved in sympathetic, thermoregulatory BAT circuits, by analyzing LepRb neurons that were transsynaptically and retrogradely traced with pseudorabies virus (PRV) injected into the BAT. Additional studies revealed that LepRb neurons in the DMH/DHA (but not the $\mathrm{mPOA}$ ) were stimulated by acute cold exposure (as measured by c-Fos induction) and project to the rRPa but not the PVN.

A large number of mPOA LepRb neurons was found to project directly to the $\mathrm{DMH} / \mathrm{DHA}$, suggesting their interaction with LepRb neurons in the DMH/DHA. mPOA LepRb neurons also projected to the rRPa. Furthermore, using LepRb-specific expression of an anterograde, transsynaptic tracer, we demonstrated that LepRb neurons indeed synaptically couple with neurons in the rRPa, thus indicating that leptin acts on several neuronal populations critical for thermoregulatory control.

Therefore, we show strong evidence for an important role of leptin in the control of sympathetic, thermoregulatory BAT circuits. The identification of LepRb neurons in thermoregulatory circuits further raises the important question to what extent thermoregulatory leptin action contributes to the severe obesity in leptin- or LepRb-deficient mice.

\section{Materials and Methods}

Animals. LepR $b^{\text {cre/cre }}$, double-homozygous LepR $b^{\text {cre/cre }}$, Gt(ROSA) 26 Sor $^{\text {tm2Sho/tm2Sho }}\left(L e p R b^{E G F P}\right.$ ), and LepR $b^{W G A}$ mice were generously provided by Dr. Martin G. Myers (University of Michigan, Ann Arbor, MI) and were described in detail previously (Leshan et al., 2006, 2009, 2010; Faouzi et al., 2007; Leinninger et al., 2009). Briefly, LepR $b^{\text {cre/cre }}$ mice express an internal ribosomal entry site-driven second cistron that encodes cre recombinase from the LepRb-specific exon of the Lepr gene. In $L e p R b^{E G F P}$ reporter mice, LepRb-specific cre recombinase was used to drive the cre-inducible expression of enhanced green fluorescent protein (EGFP) from the rosa locus, thus limiting EGFP expression to LepRb neurons (Leshan et al., 2006). LepR $b^{W G A}$ mice were generated from crossing $L e p R b^{\text {cre/cre }}$ mice with mice that carry a ubiquitously expressed cytomegalovirus promoter-driven cre-inducible wheat-germ agglutinin (WGA) transgene (iZ/WAP mice), thus resulting in mice that express WGA in LepRb neurons (LepR $b^{W G A}$ mice) (Leshan et al., 2010). LepR $b^{\text {cre/cre }}$ mice were used for adenoviral tracing experiments, $L e p R b^{E G F P}$ mice for PRV, acute cold exposure, and LepRb axonal fiber studies. $L e p R b^{W G A}$ mice were used in second-order neuron studies, and wild-type FVB mice were used for fluorogold tracing studies. Male and female mice were used in studies, and no differences between sexes were observed. All animals were bred in-house and group housed at a $12 \mathrm{~h}$ light/dark cycle with ad libitum access to food and water unless stated otherwise. All animal experiments were approved by the institutional animal care and use committee.

Pseudorabies virus infection of BAT. The retrograde and transsynaptic tracer pseudorabies virus has been extensively used in the literature to visualize neuronal populations that are involved in the autonomic regulation of peripheral organs, including the exclusively sympathetically innervated BAT (Bamshad et al., 1999; Kerman et al., 2006; Voss-Andreae et al., 2007). To identify LepRb neurons that are involved in sympathetic BAT regulation, we injected a Discosoma red (DsRed)-expressing PRV614 (Banfield et al., 2003) (kindly provided by the National Center for Experimental Neuroanatomy with Neurotropic Viruses) into the BAT of $L e p R b^{E G F P}$ reporter mice. Mice were anesthetized with isoflurane/oxygene, and BAT was exposed by an intrascapular incision. PRV614 (viral titer, $1 \times 10^{9} \mathrm{pfu} / \mathrm{ml}$ ) was then injected with a pulled glass
Table 1. Rating of PRV infected LepRb ${ }^{\text {EGFP }}$ neurons from the BAT

\begin{tabular}{llll}
\hline PRV-positive & LepRb-positive & LepRb/PRV-positive \\
neurons & neurons & neurons \\
\hline
\end{tabular}

\begin{tabular}{llll}
\hline Hypothalamus & & & \\
$\quad$ Median preoptic area & ++ & +++ & ++ \\
Paraventricular nucleus & +++++ & ++ & $-1+$ \\
Retrochiasmatic area & ++ & +++ & ++ \\
Arcuate nucleus & ++ & +++ & + \\
Lateral hypothalamic area & ++ & ++++ & $-1+$ \\
DMH/DHA & +++ & +++ & ++ \\
Ventromedial hypothalamus & + & +++ & - \\
$\quad$ Premammillary nucleus, ventral & $-/+$ & ++++ & $-1+$ \\
Midbrain & & & \\
Edinger Westphal & ++ & ++ & ++ \\
Ventral tegmental area & ++ & ++ & - \\
Red nucleus & ++ & - & - \\
Periaqueductal gray & ++ & ++ & $-1+$ \\
Doral raphe & ++ & ++ & - \\
Medulla & & & \\
Parabrachial nucleus, lateral & ++ & ++ & $-/+$ \\
Locus ceruleus & +++++ & - & - \\
Rostal ventrolateral medulla & +++ & - & - \\
Raphe pallidus & ++++ & - & - \\
Raphe obscurus & ++++ & - & - \\
Nucleus of the solitary tract & ++ & +++ & ++
\end{tabular}

+ , Only scattered neurons on one section; ++ , scattered neurons on several sections or a cluster of neurons on one section; +++ , clusters of neurons on several sections; ++++ , heavy clustering on several sections; +++++ , very heavy labeling and clustering of neurons on multiple sections.

tip attached to a $0.5 \mu$ l Hamilton syringe. Five separate injections each of $50 \mathrm{nl}$ were distributed into the right interscapular BAT depot, and injection sites were dried off to prevent any systemic leakage of the virus. Mice were single housed after viral infection for $60 \mathrm{~h}(n=2)$ and $96 \mathrm{~h}(n=4)$ and then perfused and processed as described below. Brains and spinal cords were removed, postfixed in Formalin, and cryoprotected in 30\% sucrose until additional analysis. The spinal cords of the $60 \mathrm{~h}$ postinfected mice were immunohistochemically stained for choline acetyltransferase (ChAT) and PRV; brains were processed for EGFP (LepRb) and PRV (DsRed).

Cold-induced c-Fos expression in LepRb neurons. To further identify whether LepRb neurons in the DMH are involved in thermoregulatory responses, we investigated whether LepRb neurons are stimulated by acute cold exposure. To do this, six $L e p R b^{E G F P}$ reporter mice were single housed, and food was removed to prevent randomized feeding bouts. Three of these mice were then exposed to $4^{\circ} \mathrm{C}$ for $3 \mathrm{~h}$, and the other three mice remained at room temperature $\left(21^{\circ} \mathrm{C}\right)$. For cold exposure, mice had to be moved to a new room in their home cages, thus the control group was similarly moved to a new room, to control for any handling-based c-Fos induction. Brain sections were processed for c-Fos (as a surrogate for neuronal activity) and EGFP (to identify LepRb neurons) and the number of $L e p R b^{E G F P}$ neurons colocalized with c-Fos in the DMH/DHA was estimated between groups, as described below.

Stereotaxic injections of Ad-iZ/EGFPf into the DMH. To investigate the projection sites of axonal and dendritic processes from LepRb neurons in the DMH, we used a LepRb-specific viral tracer (Ad-iZ/EGFPf, kindly provided by Dr. Martin G. Myers) that expresses farnesylated EGFP (EGFPf) during cre recombination in LepR $b^{\text {cre/cre }}$ mice, as described previously (Leinninger et al., 2009; Leshan et al., 2009). The farnesylation anchors EGFP to the cell membrane and thus increases the visualization of thin axonal processes. For stereotaxic injections, LepR $b^{\text {cre/cre }}$ mice were anesthetized with isoflurane/oxygen, and the head was mounted in a stereotaxic frame (David Kopf Instruments). An incision was made to expose the skull, an access hole was drilled at coordinates $1.4 \mathrm{~mm}$ caudal and $0.3 \mathrm{~mm}$ lateral to bregma, and a guide cannula was inserted $4.2 \mathrm{~mm}$ ventral to bregma. An injector filled with Ad-iZ/EGFPf and attached to a $0.5 \mu \mathrm{l}$ Hamilton syringe was inserted in the guide, and a volume of $400 \mathrm{nl}$ was slowly infused in the DMH tissue $(10 \mathrm{nl} / 30 \mathrm{~s})$. Guide and injector were removed, the skull access was sealed with bone wax, and the skin was 
A
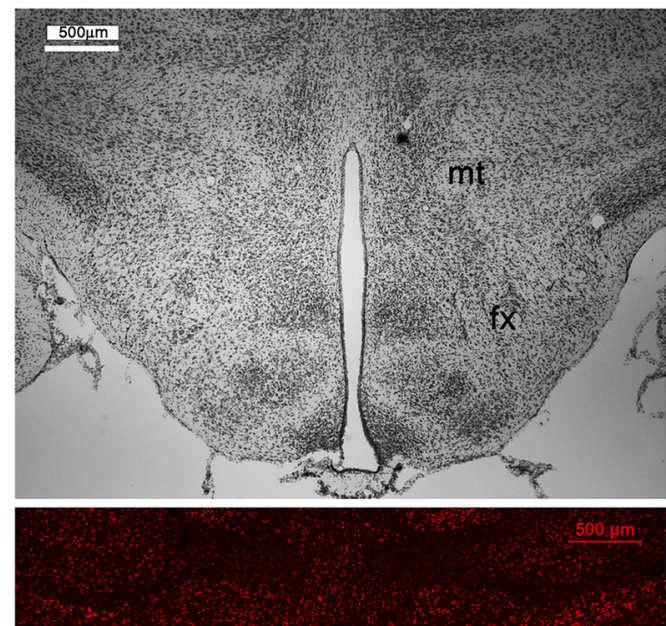

$\mathrm{mt}$
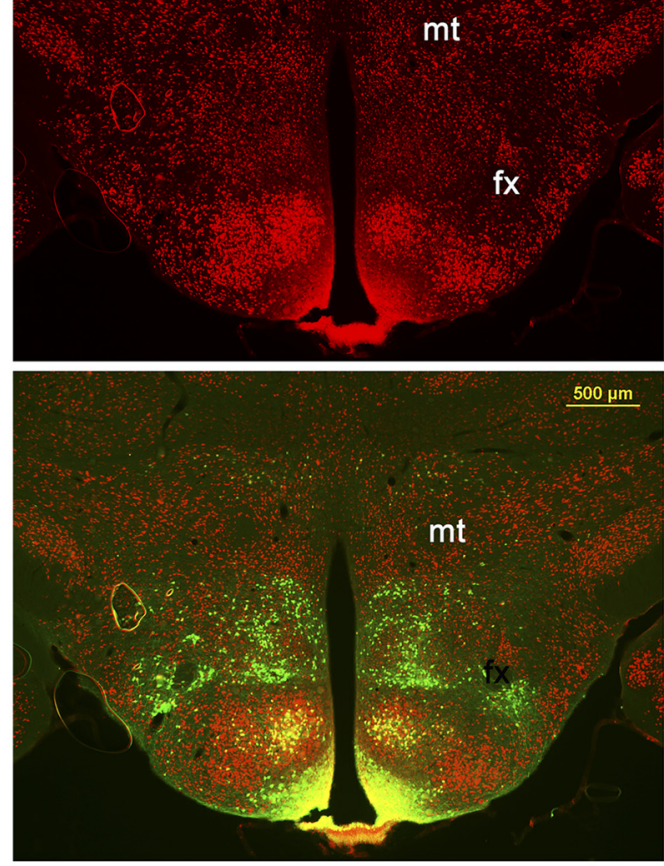

B
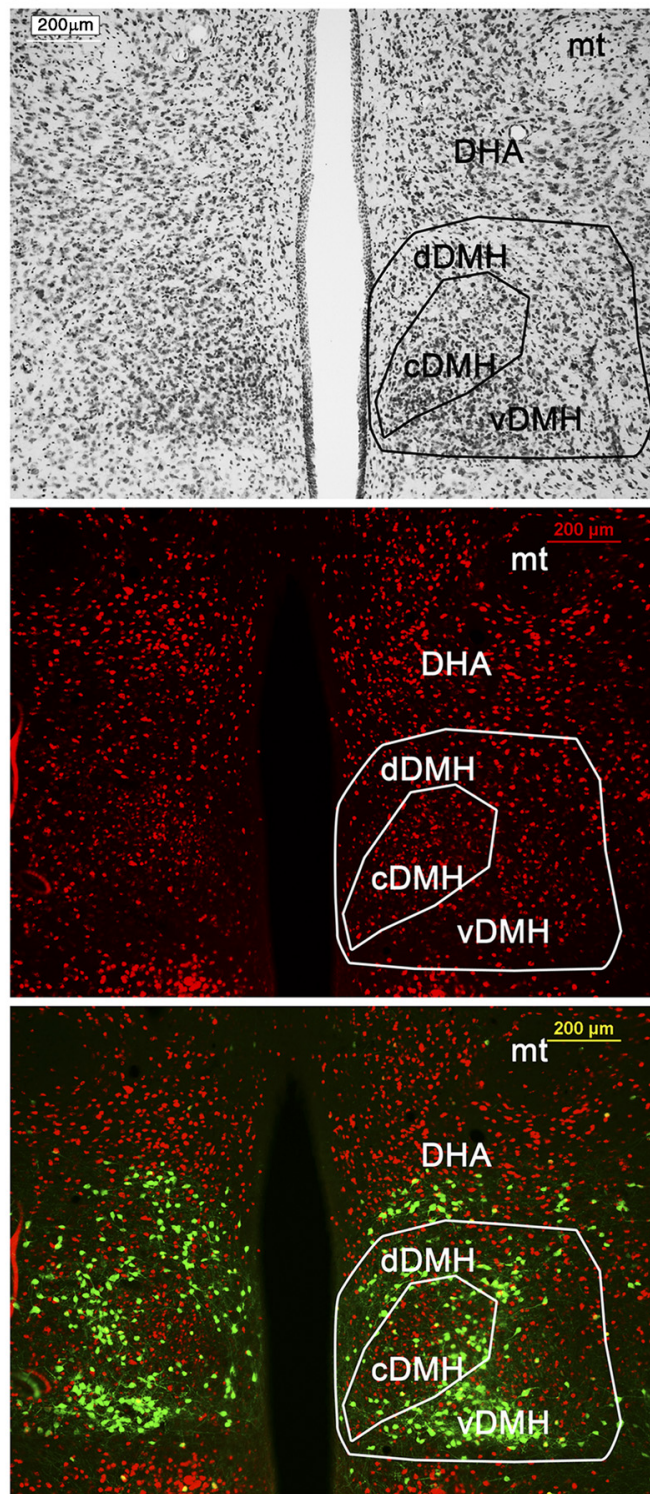

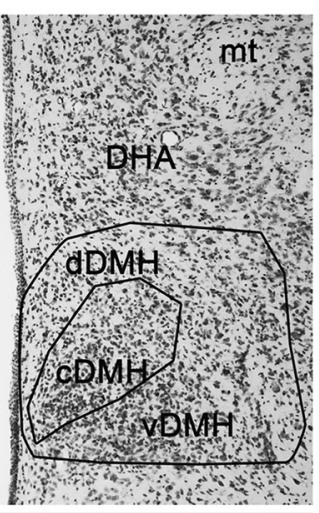

$\mathrm{mt}$

$200 \mu \mathrm{m}$

mt

C
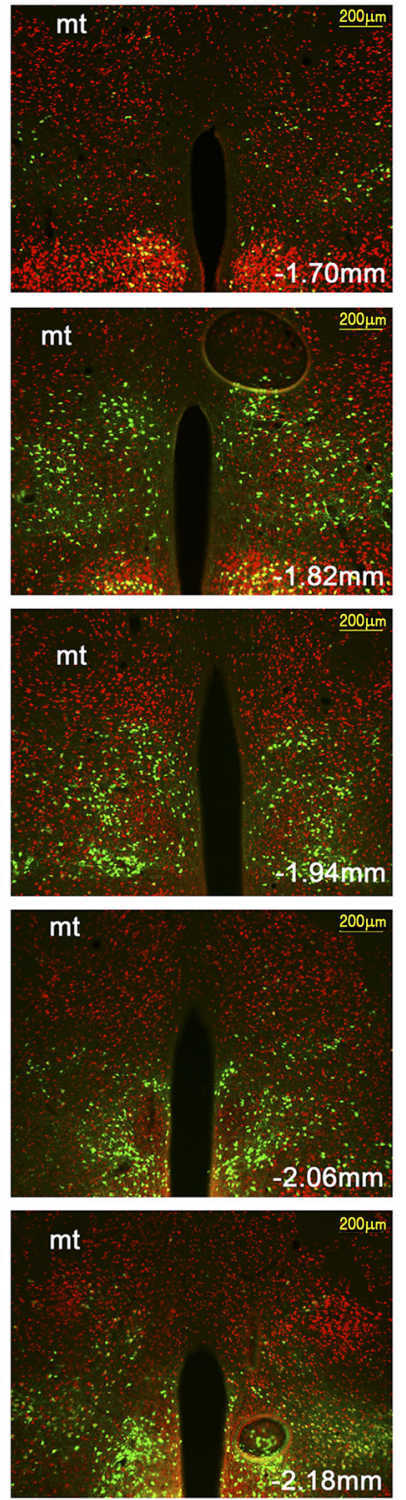

Figure 1. Neuroanatomical localization of LepRb neurons in the DMH. $\boldsymbol{A}, \boldsymbol{B}$, Immunohistochemical staining of a LepRb ${ }^{E G F P}$ mouse brain for Nissl (top), NeuN (middle), and counterstained with $L_{\text {LepRb }}{ }^{E G F P}$ (bottom). In the overview $(\boldsymbol{A})$, the outline of the DMH with regard to the third ventricle $(3 \mathrm{~V})$, $\mathrm{mt}$, and $\mathrm{fx}$ are shown. In the high magnification $(\boldsymbol{B})$, the compact DMH is seen by the more cell-dense area in the DMH, and dDMH and vDMH are located dorsal and ventral to the CDMH, respectively. The DHA is defined as the area between the mt and dDMH. C, Rostral to caudal extend of LepRb neurons in the DMH in relation to the neuronal marker NeuN and mt as a landmark.

closed with wound clips. Analgetics were applied once to the incision site (bupivacaine/lidocaine, $5 \mathrm{mg} / \mathrm{kg}$ ) and subcutaneously during recovery every $12 \mathrm{~h}$ for $2 \mathrm{~d}$ (buprenorphine, $10 \mu \mathrm{g} / \mathrm{kg}$ ). After the surgery, mice were single housed for $5 \mathrm{~d}$ to allow for viral transport of EGFPf expression before transcardial perfusion with $10 \%$ neutral buffered Formalin to collect brains for additional analysis.

Retrograde tracing experiments with fluorogold. To investigate the exact anatomical distribution of LepRb neurons that project to the PVN, rRPa, and $\mathrm{DMH} / \mathrm{DHA}$, we stereotaxically injected mice with the retrograde tracer fluorogold (FG) (Hydroxystilbamid; Invitrogen) into the PVN, the rostral medullary raphe (RMR) (which includes the $\mathrm{rRPa}$ ), and the DMH/DHA. Surgical procedures were similar as described above; however, for increased stereotaxic precision, we used the stereotaxic alignment system (David Kopf Instruments). In each case, we injected $10 \mathrm{nl}$ of a 2\% FG solution in sterile saline into the PVN $(0.8 \mathrm{~mm}$ caudal, $0.25 \mathrm{~mm}$ lateral, and $5 \mathrm{~mm}$ ventral to bregma), RMR/rRPa (6.0 mm caudal, $0 \mathrm{~mm}$ lateral, and $5.75 \mathrm{~mm}$ ventral to bregma), DMH/DHA (1.8 $\mathrm{mm}$ caudal, $0.25 \mathrm{~mm}$ lateral, and $5 \mathrm{~mm}$ ventral to bregma). After the surgery, animals were single housed, and FG transport was allowed for $5 \mathrm{~d}$. Animals received an intraperitoneal leptin injection (from National Hormone and Pituitary Program and Dr. Parlow, Harbor-University of California, Los Angeles Medical Center, Torrance, CA) $1 \mathrm{~h}$ before perfusion to allow later immunohistochemical identification of LepRb neurons by staining for leptin-induced STAT3 phosphorylation (pSTAT3).

Perfusion and immunohistochemistry. For immunohistochemical analysis, mice were deeply anesthetized with an overdose of pentobarbital (4 $\mathrm{mg} / \mathrm{kg}$ ) and perfused with saline, followed by $10 \%$ Formalin via the left ventricle. Brains or spinal cords were removed, postfixed in Formalin, and cryoprotected in 30\% sucrose. Brains were sliced into four series of $30 \mu \mathrm{m}$ sections and processed for free-floating immunohistochemistry (IHC) as described previously (Faouzi et al., 2007). Briefly, sections were pretreated consecutively with $\mathrm{H}_{2} \mathrm{O}_{2}$ in ice-cold methanol, $0.3 \%$ glycine, and $0.1 \%$ SDS for pSTAT3 IHC and/or blocked in 3\% normal donkey serum and then incubated with primary antibodies [rabbit anti-pSTAT3, 1:1000 (Cell Signaling Technology); rabbit anti-c-Fos, 1:5000 (EMD Biosciences); chicken anti-GFP, 1:1000 (Abcam); rabbit anti-DsRed, 1:1000 
(Clontech); goat anti- $\beta$-galactosidase, 1:3000 (Covance); goat-anti-ChAT, 1:1000 (Millipore Corporation); goat anti-WGA, 1:1000 (Vector Laboratories); and mouse anti-neuronal-specific nuclear protein (NeuN), 1:1000 (Millipore Corporation)] overnight at room temperature or for $2 \mathrm{~d}$ at $4^{\circ} \mathrm{C}$. Sections were then washed and incubated in secondary antibodies labeled with either Alexa fluorophores (Invitrogen) or with biotin for subsequent visualization with the diaminobenzine procedure.

Analysis of data and quantification of neurons. IHC staining was visualized with a fluorescent microscope (Olympus BX51), and images were taken with a digital camera (Olympus DP30BW) using appropriate filters for different fluorophores or bright-field illumination for DAB stain. Identical images were taken for double IHC, overlaid, and pseudocolored using Olympus Software and Adobe Photoshop (Adobe Systems). Contrast and brightness were adjusted for fluorescent signals with Adobe Photoshop (Adobe Systems) for better visualization of neurons.

For Ad-iZ/EGFPf tracing from LepRb neurons in the $\mathrm{DMH}$, we analyzed four mice with correct injections into the DMH and showed representative images of projection sites in the $\mathrm{mPOA}, \mathrm{DMH}, \mathrm{PVN}$, and rRPa in Figure 4.

For FG tracing experiments, we focused our analysis on the mPOA and DMH/DHA to investigate colocalization of LepRb neurons with FG-traced neurons from the RMR/rRPa $(n=$ $4)$, DMH/DHA $(n=3)$, or PVN $(n=2)$. Representative images were shown for the $\mathrm{DMH} /$ DHA and mPOA, and, in some cases, we generated schematic drawings of the images to emphasize the number and distribution of colocalized LepRb/FG neurons compared with the remaining single-labeled LepRb neurons.

Estimates of cell counts were performed as described previously (Münzberg et al., 2007). Briefly, all images were taken as described above with all settings identical (exposure time, brightness, and contrast) to ensure the comparability between images of different sections and animals.

To quantify the number of leptin-induced pSTAT3 neurons that are colocalized with $L e p R b^{E G F P}$ in the DMH, we counted cells in three $L e p R b^{E G F P}$ brains after a $1 \mathrm{~h}$ leptin stimulation. Images of the DMH were taken between bregma level -1.8 to $-2.0 \mathrm{~mm}$, resulting in three DMH sections, and cell counts were performed bilaterally, including the ventral (v) $\mathrm{DMH}$, compact (c) DMH, dorsal (d) DMH, and DHA. The mean number of pSTAT3/EGFP double-labeled neurons between the DMH sections was expressed as the percentage of the total number of pSTAT3positive neurons.

For PRV experiments, we analyzed all LepRb-expressing sites for their colocalization with PRV. The relative PRV infection, abundance of LepRb-expressing neurons, as well as colocalized neurons were evaluated in three brains (one brain was excluded because of GFP leakage and thus insufficient GFP staining) and reported in Table 1. To further quantify the number of PRV/EGFP colabeled neurons, we took images of three PRV614-injected mouse brains. All sites showing PRV/LepRb labeling were quantified. The following number of sections were taken and quantified for the specific sites: one to two sections in the mPOA, one section in the DMH/DHA (between bregma level -1.8 to $-1.9 \mathrm{~mm}$ ), one section in the retrochiasmatic area ( $\mathrm{RCh})$, three to four sections in the Edinger Westphal nucleus (EW), and one to two sections in the nucleus of the referred to as $\mathrm{MPOA}$ ).
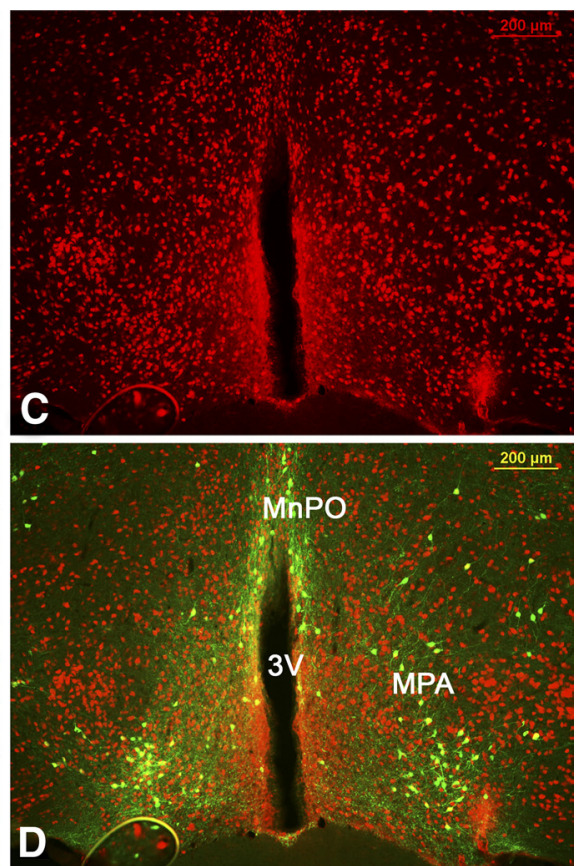

$3 \mathrm{~V}$

Figure 2. Neuroanatomical location of LepRb neurons in the MPOA. $\boldsymbol{A}, \boldsymbol{B}$ and $\boldsymbol{C}, \boldsymbol{D}$ show two $\mathrm{mPOA}$ levels in a LepRb ${ }^{E G F P}$ mouse stained for LepR $b^{E G F P}(\boldsymbol{B}, \boldsymbol{D})$ and the neuronal marker NeuN $(\boldsymbol{A}-\boldsymbol{D})$. LepRb neurons are found in the MPA and MnPO (collectively
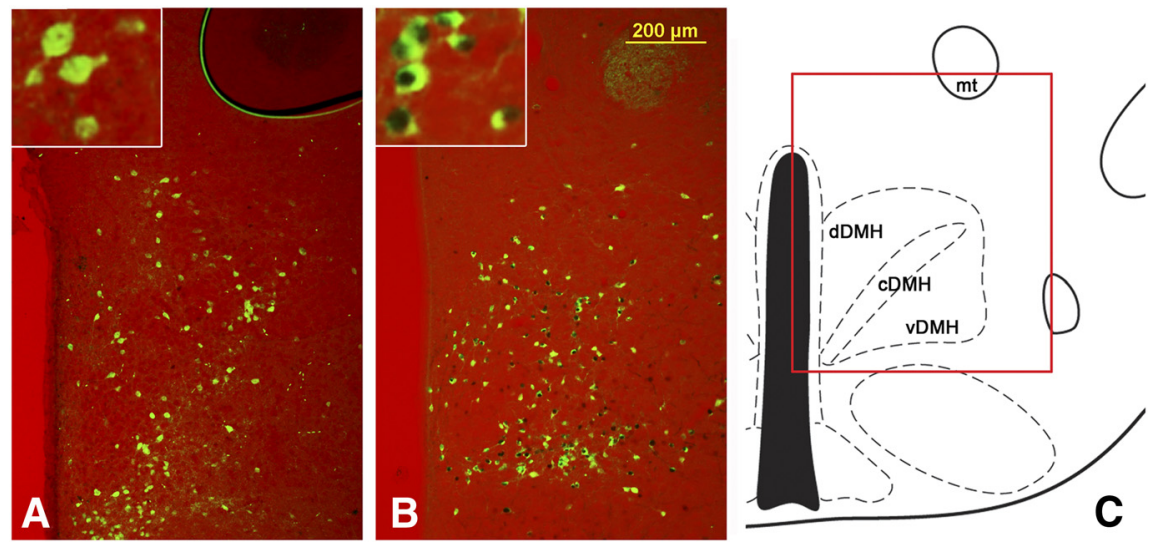

Figure 3. LepRb ${ }^{E G F P}$ mice treated with PBS $(\boldsymbol{A})$ or leptin $(1 \mathrm{mg} / \mathrm{kg} ; \boldsymbol{B})$ and stained for pSTAT3 (nuclear black stain) and EGFP (green) to demonstrate leptin-induced pSTAT3 in LepRb ${ }^{\text {EGFP }}$ neurons $(n=3)$. C, Schematic drawing of the area in $\boldsymbol{A}$ and $\boldsymbol{B}$.

solitary tract (NTS). The number of PRV/LepRb colabeled neurons was expressed as percentage of the total number of PRV-labeled neurons in those sites.

To quantify cold-induced c-Fos in $L e p R b^{E G F P}$ neurons, images of five to six animals per group (room temperature, $n=5 ; 3 \mathrm{~h}$ cold exposure, $n=6$ ) were taken. For the DMH/DHA area, one image per brain was used for cell counts, and LepRb neurons were counted in total as well as for their colocalization with c-Fos. We did not quantify colocalized cFos/LepRb neurons in the mPOA, because we could not identify colocalized c-Fos/LepRb neurons in either group (data not shown). The total number of counted LepRb neurons was presented to demonstrate the comparison of similar LepRb populations between animals. The number of c-Fos colocalized LepRb neurons was expressed as percentage of the total number of LepRb neurons in the quantified area. Statistical significance was tested with a Student's $t$ test, and a statistical significance was accepted at $p<0.05$. These cell counts were not meant to give precise cell numbers of stimulated LepRb neurons in the DMH/DHA but served as estimates for cold-induced neuronal activity in LepRb neurons in the DMH/DHA compared with the group kept at room temperature. 

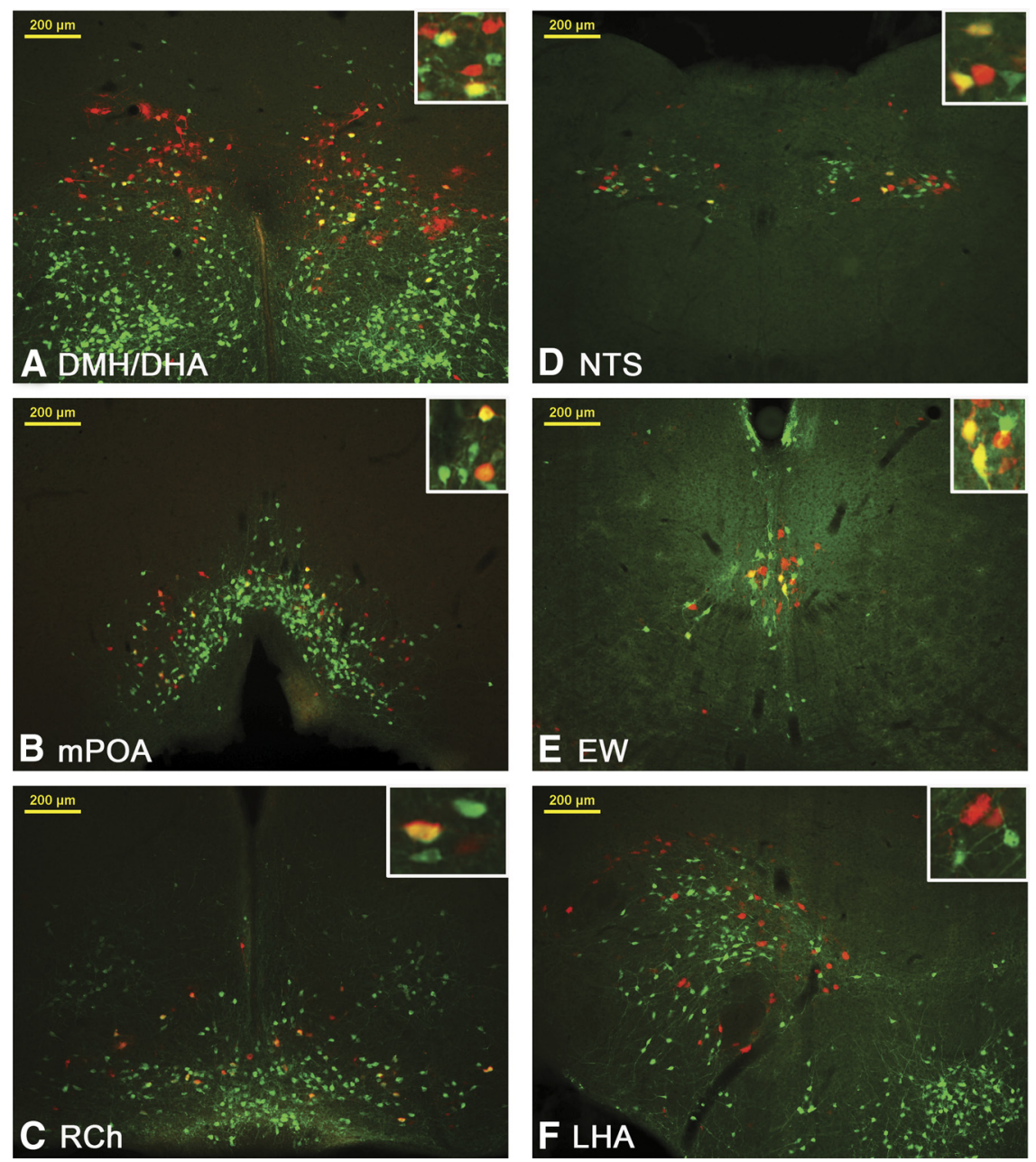

Figure 4. Representative images from LepRb ${ }^{E G F P}$ mice $96 \mathrm{~h}$ after PRV infection of the BAT. Transsynaptically and retrogradely PRV (red stain) traced LepRb ${ }^{E G F P}$ (greed stain) neurons are found in the DMH/DHA $(\boldsymbol{A}), \mathrm{mPOA}(\boldsymbol{B}), \operatorname{RCh}(\boldsymbol{C})$, NTS $(\boldsymbol{D})$, and EW $(\boldsymbol{E})$. Other PRV- and LepRb-positive sites, such as the lateral hypothalamic area (LHA, $\boldsymbol{F})$, did not show colocalized neurons.

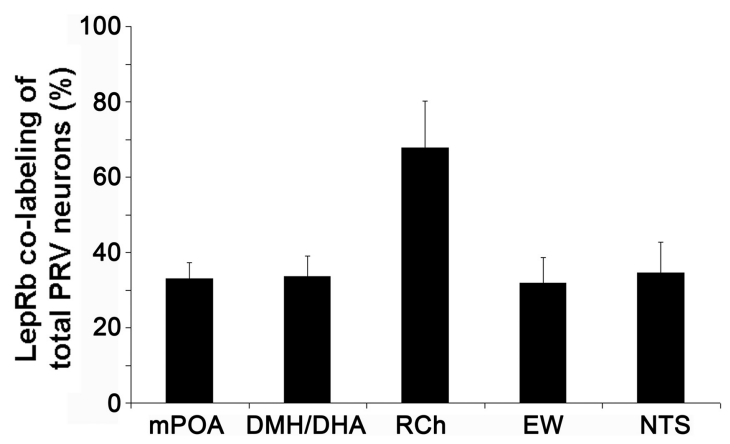

Figure 5. Quantification of PRV/LepRb ${ }^{E G F P}$-positive neurons. Percentage of double-labeled neurons compared with total PRV-labeled neurons in different brain sites $(n=3)$.

\section{Results}

Anatomical outline of LepRb neurons in the DMH, DHA, and $\mathrm{MPOA}$

In this study, we describe a population of LepRb neurons at the border of the DMH and DHA (DMH/DHA). In the mouse brain atlas (Paxinos and Franklin, 2004), the DHA is referred to as posterior hypothalamus $(\mathrm{PH})$ and describes the area between the $\mathrm{DMH}$ and mammillothalamic tract $(\mathrm{mt})$, whereas in the rat brain atlas (Paxinos and Watson, 1998), the rostral portion of the $\mathrm{PH}$ is specifically described as DHA. In the rat, DMH/DHA neurons have been particularly highlighted to project to the raphe pallidus (Hosoya et al., 1987, 1989; Hermann et al., 1997) and to be important in thermoregulatory control (Dimicco and Zaretsky, 2007; Morrison et al., 2008). Our findings on LepRb DMH/DHA neurons as outlined below show close similarity to the excitability and connectivity demonstrated in the rat; thus, here we adopted the rat terminology of DMH/ DHA neurons.

To clarify the anatomical localization of LepRb neurons within the mouse DMH and DHA, we counterstained brains from $L e p R b^{E G F P}$ mice for GFP and the neuronal marker NeuN and further processed adjacent sections for Nissl stain (Fig. 1). In an overview (Fig. 1A), the distribution of $L e p R b^{E G P F}$ neurons compared with common neuroanatomical landmarks, such as $\mathrm{mt}$ and fornix ( $\mathrm{fx}$ ) is demonstrated. The middle portion of the DMH can be subdivided into three distinct areas based on the mouse brain atlas (Paxinos and Franklin, 2004), whereas the most rostral (Fig. 1C, bregma $-1.7 \mathrm{~mm}$ ) and caudal (Fig. $1 C$, bregma $-2.18 \mathrm{~mm}$ ) portions are simply referred to as DMH. The compact DMH is named after its denser neuronal aggregation, which is recapitulated with $\mathrm{NeuN}$ and Nissl stain (Fig. 1A,B). The ventral and dorsal DMH lay below and above the $\mathrm{CDMH}$, respectively, and show less dense NeuN labeling. Laterally, the DMH is bordered by the perifornical area and lateral hypothalamus, and the fornix serves as a general landmark to visualize the separation of DMH and lateral hypothalamus. The vDMH is ventrally delimited by the ventromedial hypothalamus, whereas the $\mathrm{dDMH}$ is dorsally confined by the DHA. The DHA is described as the area between the $\mathrm{mt}$ and the $\mathrm{dDMH}$.

LepRb neurons are most dense and abundant in the vDMH but are also found in the $\mathrm{dDMH}$ and $\mathrm{CDMH}$, but a noticeable area with less LepRb neurons is found in the cDMH. LepRb neurons in the dDMH extend further into the dorsal portion of the DHA, and this population is referred to as DMH/DHA LepRb neurons. In Figure $1 C$, the rostrocaudal extent of LepRb neurons in the $\mathrm{DMH}$ is shown, including the mt as anatomical landmark. We found that the distribution of LepRb neurons recapitulate the anatomical outline of the DMH sufficiently as defined by NeuN staining. Thus, in the following experiments, we use the distribution of LepRb neurons in the DMH/DHA and the mt as anatomical landmarks.

We further investigate the projections of LepRb neurons in the preoptic area, which consists of several specific subregions. The LepRb population investigated in this study is located between bregma 0.65 and $0.25 \mathrm{~mm}$ according to the coordinates in the mouse brain atlas (Paxinos and Franklin, 2004) in the median preoptic nucleus (MnPO) and medial preoptic area (MPA) (Fig. 2 ) that we collectively refer to as median preoptic area (mPOA). 
A
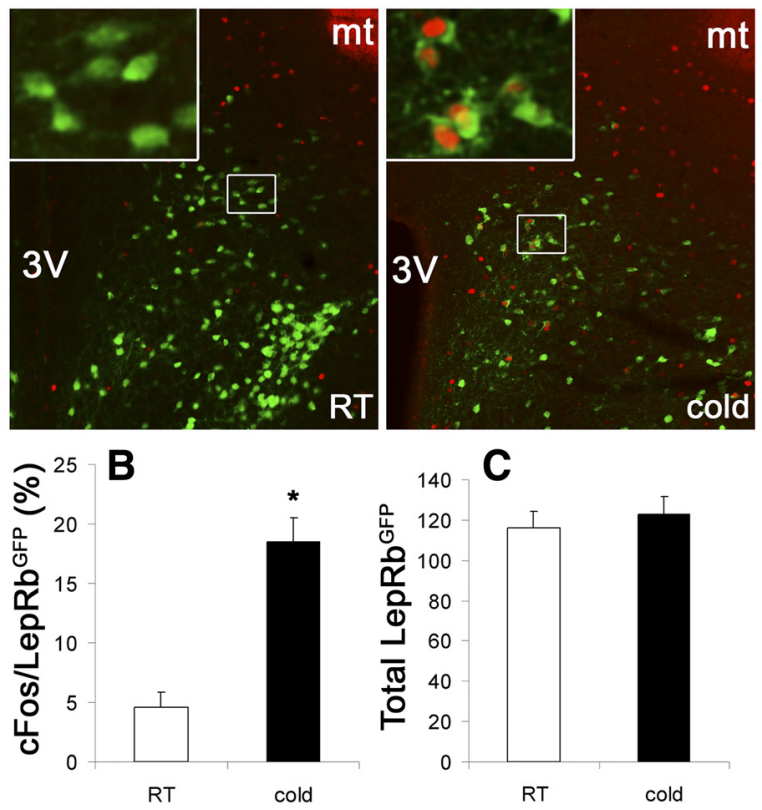

Figure 6. $\quad \boldsymbol{A}$, Immunohistochemistry of c-Fos induction (red) in LepRb ${ }^{E G F P}$ neurons (green) after 3 hacute cold exposure $(n=6)$ compared with room temperature (RT) conditions $(n=5)$. $\boldsymbol{B}$, Percentage of colocalized c-Fos/LepRb $b^{\text {EGFP }}$ neurons relative to total LepRb ${ }^{E G F P}$ neurons in the $\mathrm{DMH} / \mathrm{DHA}$ at room temperature versus $3 \mathrm{~h}$ acute cold exposure. $\boldsymbol{C}$, Total number of $L e p R b^{E G F P}$ neurons in the DMH/DHA of mice kept at room temperature or after $3 \mathrm{~h}$ cold exposure. ${ }^{*} p<$ $0.00000001, t$ test. $3 \mathrm{~V}$, Third ventricle.

\section{Detection of LepRb neurons in the DMH and mPOA}

Immunohistochemical detection of LepRb with specific antibodies has been difficult in the past and commercially available antibodies either are unspecific or lack sensitivity for immunohistological detection. LepRb signals via the JAK2/ STAT3 signaling pathway, and leptin-induced pSTAT3 has been proven an excellent marker of functional LepRb neurons in the hypothalamus and has been used extensively by us and others (Hosoi et al., 2002; Münzberg et al., 2003; Dhillon et al., 2006; Faouzi et al., 2007). For example, whereas little baseline pSTAT3 is seen in vehicle-treated mice, leptin treatment induced pSTAT3 in a typical pattern similar to the expression of LepRb. In contrast, although pSTAT3 can be induced by many other pathways, e.g., inflammatory cytokines (Rummel et al., 2005), LepRbdeficient mice lack baseline and leptin-induced pSTAT3 immunoreactivity (Faouzi et al., 2007). Furthermore, neuron-specific deletion of long-form leptin receptors resulted accordingly in neuron-specific absence of leptin-induced pSTAT3 (Dhillon et al., 2006), thus further indicating that leptin-induced pSTAT3 indeed is a correlate of direct LepRb function rather than secondary events. However, in some cases, the required leptin stimulation may interfere with the experimental outcome (e.g., induction of neuronal activity). Thus, the use of reporter mice with conditional EGFP expression in LepRb neurons (LepR $b^{E G F P}$ mice) has been a valuable additional approach to detect LepRb in nontreated animals (Leshan et al., 2006, 2009; Leinninger et al., 2009).

$L e p R b^{E G F P}$ reporter mice do not express EGFP in all leptininduced pSTAT3 neurons likely as a result of cre recombination efficiency as the number of $L e p R b^{E G F P}$ neurons increases with alleles for cre and loxP. Thus, we use double-homozygous $L e p R b^{E G F P}$ reporter mice in our studies, in which $\sim 80$ or $96 \%$ of all leptin-induced pSTAT3 neurons are colocalized with $L e p R b^{E G F P}$ as

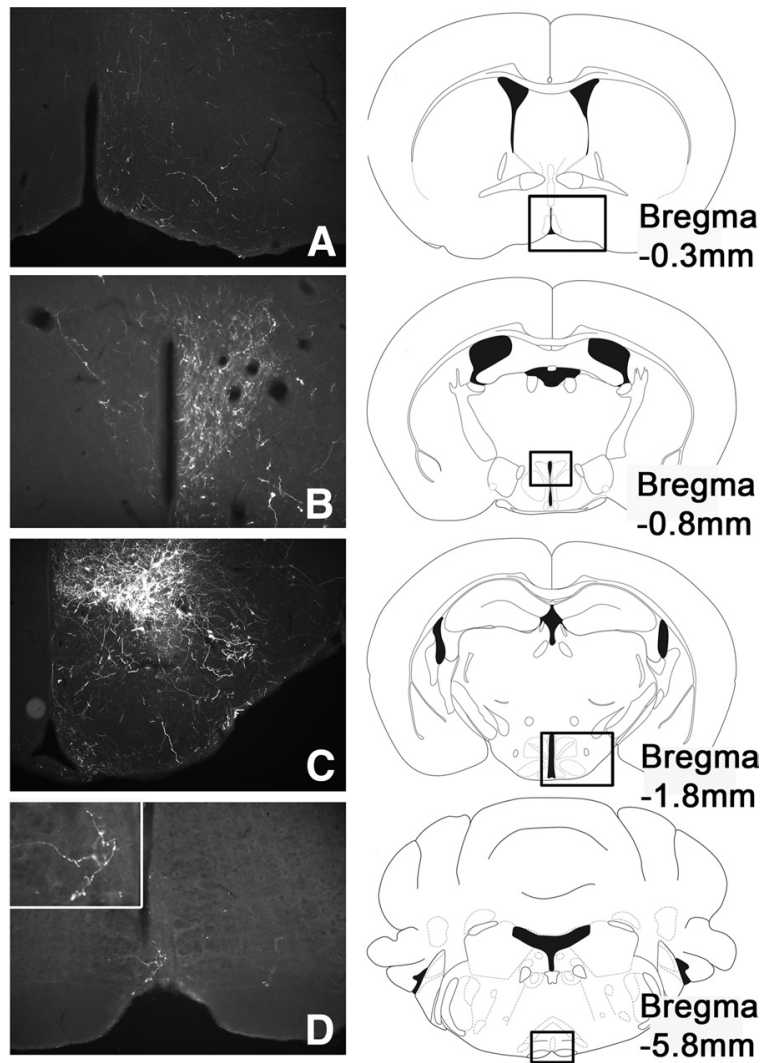

Figure 7. Representative images of a LepR $b^{\text {cre/cre }}$ mouse with DMH-specific injection of creinducible Ad-iZ/EGFPf ( $n=4)$. Immunohistochemical detection of EGFPf shows projections into the $\mathrm{MPOA}(\boldsymbol{A}), \operatorname{PVN}(\boldsymbol{B}), \operatorname{DMH}(\boldsymbol{C})$, and $\mathrm{rRPa}(\boldsymbol{D})$.

evaluated in the lateral hypothalamus and ventral premammillary nucleus, respectively (Leinninger et al., 2009; Leshan et al., 2009). To validate in the DMH that the majority of pSTAT3 neurons recapitulate EGFP reporter expression, we quantified the number of neurons showing $L e p R b^{E G F P}$ expression and leptin-induced pSTAT3 (after $1 \mathrm{~h}$ leptin treatment) in the DMH and found as well that the majority $(72 \pm 2.4 \%)$ of leptininduced pSTAT3 neurons are colocalized with EGFP (Fig. 3B). Thus, leptin-induced pSTAT3 and $L e p R b^{E G F P}$ are both valid methods to detect central LepRb neurons.

LepRb neurons in the DMH, mPOA, RCh, EW, and NTS are involved in sympathetic BAT circuits

PRV has been extensively used in the literature to label neuronal populations in the brainstem and forebrain that are involved in sympathetic BAT circuits (Bamshad et al., 1999; Cano et al., 2003; VossAndreae et al., 2007), and this technique has helped to characterize neuronal populations in the DMH/DHA and mPOA as important regulator of thermogenesis (Nakamura et al., 2004; Dimicco and Zaretsky, 2007). Although some of these neuronal circuits have been well characterized in recent years (Dimicco and Zaretsky, 2007; Morrison et al., 2008; Yoshida et al., 2009), much less is known about endogenous regulators of these neuronal circuits.

Leptin has been repeatedly noted to be involved in thermoregulatory events, e.g., leptin deficiency and lack of LepRb results in an inability to adjust to acute cold exposure, resulting in severe hypothermia and even death (Trayhurn et al., 1976, 1977). However, very little is known about the neuronal circuits involved.

LepRb neurons are found in the DMH/DHA and $\mathrm{mPOA}$, and we thus hypothesized that leptin action in the DMH/DHA and 


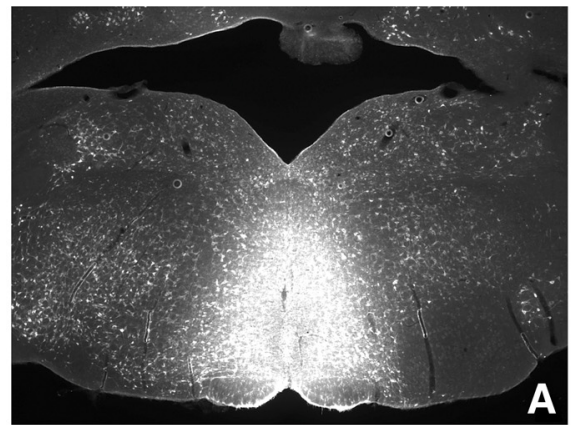

pSTAT3 pSTAT3/FG
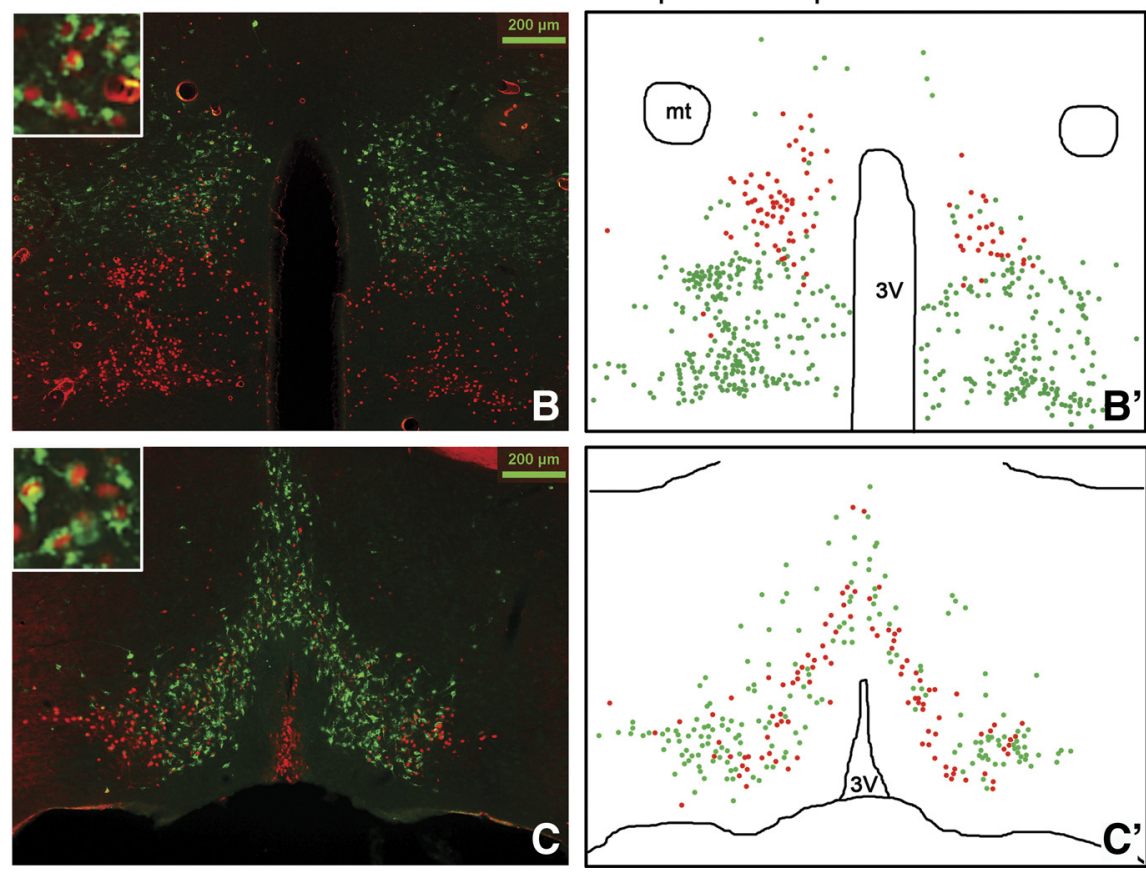

Figure 8. Stereotaxic injection of the retrograde tracer FG into the RMR $(\boldsymbol{A}, n=4)$ and immunohistochemical detection of retrogradely labeled FG (green) in LepRb neurons (leptin-induced pSTAT3, red) in the DMH/DHA (B) and mPOA (C). Schematic drawings of double-labeled FG/pSTAT3 neurons (red dots) in contrast to non-FG-labeled pSTAT3 neurons (green dots) in the $\mathrm{DMH} / \mathrm{DHA}\left(\boldsymbol{B}^{\prime}\right)$ and $\mathrm{mPOA}\left(\boldsymbol{C}^{\prime}\right) .3 \mathrm{~V}$, Third ventricle.

mPOA might be involved in its thermoregulatory functions. To identify LepRb neurons involved in sympathetic BAT circuits, we injected PRV into the BAT of $L e p R b^{E G F P}$ mice for $60 \mathrm{~h}$ to confirm specificity of PRV infection to the BAT and an extended time of $96 \mathrm{~h}$ to capture the maximal PRV infection of LepRb neurons.

After $60 \mathrm{~h}$ of PRV infection, PRV was found confined to the thoracic portion of the spinal cord (supplemental Fig. $1 A, B$, available at www.jneurosci.org as supplemental material) specifically in the preganglionic intermediolateral bundle (IML), as identified by the expression of ChAT. All PRV-infected neurons in the spinal cord after $60 \mathrm{~h}$ were colocalized with ChAT, indicating exclusive PRV infection to the IML (supplemental Fig. 1C, available at www.jneurosci.org as supplemental material).

After 96 h of PRV infection, we found typical infection patterns in the brain that have been described in detail by others (Bamshad et al., 1999; Cano et al., 2003; Voss-Andreae et al., 2007), generally in the brainstem (raphe nuclei), midbrain (red nucleus, periaqueductal gray), and hypothalamus (PVN, mPOA, $\mathrm{DMH} / \mathrm{DHA}, \mathrm{RCh}$ ), and a general rating of most of these areas is reported in Table 1 .

We then analyzed all LepRb-expressing brain sites for PRV infections and found retrogradely PRV-traced LepRb neurons in the $\mathrm{DMH} / \mathrm{DHA}$ (34 $\pm 5 \%$ of total PRV neurons) and mPOA (33 $\pm 4 \%$ of total PRV neurons) (Figs. 4A, B, 5). PRV infection of the DMH/DHA was typically restricted to the rostral DMH/DHA (corresponding to bregma level -1.82 to -1.94 $\mathrm{mm}$ ), which has been also reported by others (Cano et al., 2003), and did not extend to the $\mathrm{mt}$; accordingly, PRV/LepRb neurons were found in the rostrodorsal portion of the DMH/DHA (Fig. 1A). We also consistently found PRV-traced LepRb neurons in the RCh, NTS, and EW $(68 \pm 12,32 \pm 7$, and $35 \pm 8 \%$ of total PRV neurons, respectively) (Figs. $4 C-F, 5$ ), which have not been specifically investigated as important thermoregulatory sites in the literature and will need additional investigation for their role in thermoregulatory leptin action.

In contrast, several other sites with both LepRb expression and PRV labeling (e.g., the PVN, lateral hypothalamic area, periaqueductal gray, parabrachial nucleus) did not show any colocalization of LepRb and PRV, although an occasional PRV-infected LepRb neuron was found in these sites (Table 1). However, as found by others (Cano et al., 2003), PRV injection from the BAT did vary between animals, e.g., PRV infection of LepRb neurons in the DMH/DHA varied from 15 to $50 \%$ in the analyzed brains. Thus, a lack of PRV/LepRb colocalization cannot completely rule out their involvement in thermoregulatory circuits.

\section{Acute cold exposure stimulates LepRb neurons in the DMH/DHA but not LepRb neurons in the mPOA}

Recent work suggests that thermoregulatory neurons in the $\mathrm{DMH} / \mathrm{DHA}$ receive inhibitory inputs from the mPOA and that DMH/DHA neurons directly project to the raphe pallidus in the medulla (Dimicco and Zaretsky, 2007; Morrison et al., 2008). These neurons are differentially regulated by acute cold exposure, with the $\mathrm{mPOA}$ being inhibited, thus reducing GABAergic inputs onto DMH/DHA neurons and consequently leading to a stimulation of DMH/DHA neurons during cold exposure (Cano et al., 2003; Nakamura et al., 2005; Yoshida et al., 2009).

We used this paradigm to further strengthen our findings that LepRb neurons in the DMH/DHA and mPOA represent these thermoregulatory populations and investigated whether LepRb neurons in the DMH/DHA, but not the mPOA, are stimulated by acute cold exposure. Indeed, 3 h cold exposure significantly induced c-Fos (as a surrogate for neuronal activity) in LepRb neurons within the DMH/DHA (Fig. 6) but not in LepRb neurons in the mPOA as well as the remaining DMH (data not shown), thus further indicating a significant involvement of leptin signaling in thermoregulatory circuits in the DMH/DHA and mPOA.

\section{LepRb projections from the $\mathrm{DMH}$}

Blocking of GABAergic inputs to the DMH results in increased BAT thermogenesis (Zaretskaia et al., 2002) and inhibition of DMH neurons prevents BAT thermogenesis (Zaretskaia et al., 2003; Nakamura et al., 2005), which involves at least in part signaling via coldresponsive neurons in the DMH/DHA that project to the $\mathrm{rRPa}$ 
(Dimicco and Zaretsky, 2007). However, $\mathrm{DMH}$ neurons also densely innervate the PVN to regulate neuronal activity (ter Horst and Luiten, 1986; Thompson et al., 1996; Bailey and Dimicco, 2001; Zaretskaia et al., 2002), although the involvement of this circuit in thermoregulation is less clear.

Thus, we aimed to investigate the neuronal projections specifically from LepRb neurons in the $\mathrm{DMH}$ via targeting a creinducible EGFP adenoviral vector to the DMH of LepR $b^{\text {cre/cre }}$ mice. The additional farnesylation of EGFP (EGFPf) in this viral construct targeted EGFP to the cell membrane for enhanced visualization of thin axonal projections.

Indeed, we found that LepRb neurons from the DMH densely project to the PVN, as well as sparse but consistent projections to the rRPa. Furthermore, we found terminal fields in the mPOA, bed nucleus of stria terminalis, lateral septum, $\mathrm{RCh}$, arcuate nucleus (ARC), periaqueductal gray, and within the DMH (Fig. 7 and data not shown). Collectively, these data suggest that thermoregulatory LepRb neurons in the $\mathrm{DMH}$ indeed may interact via the $\mathrm{rRPa}$ and/or PVN, while also interacting with several hypothalamic sites that are likely not all involved in thermoregulatory function.

\section{LepRb neurons in the DMH/DHA and mPOA innervate the raphe pallidus}

To further distinguish whether LepRb neurons in the DMH/DHA project to the rRPa or the PVN, we injected the retrograde tracer fluorogold into the RMR (including the rRPa) (Fig. 8A) or PVN (Fig. 9A).

We found several LepRb DMH neurons retrogradely labeled from the PVN, but none were found in the DMH/DHA area (Fig. $9 B)$. In contrast, we found the majority of LepRb neurons in the DMH/DHA (Fig. $8 B, B^{\prime}$ ) and a large portion of LepRb neurons in the mPOA (Fig. $8 C, C^{\prime}$ ) colocalized with FG from the RMR. Because of the small size of the rRPa in the mouse, it is difficult to confine FG injections solely to this site; thus, we used injections to the RMR to represent neurons projecting into the $\mathrm{rPa}$ (Fig. $8 \mathrm{~A}$ ). This is supported by the fact that FG injections into the RMR, excluding the rRPa, showed only a few FG-traced neurons in the DMH/DHA or mPOA and only occasionally a colocalization with LepRb neurons (supplemental Fig. 2, available at www. jneurosci.org as supplemental material).

These results, together with our adenoviral tracing studies, support that LepRb neurons in the DMH/DHA indeed represent thermoregulatory neurons that act via the $\mathrm{rRPa}$ to regulate BAT thermogenesis. Furthermore, we also show that LepRb neurons in the mPOA project to the $\mathrm{rRPa}$, indicating that thermoregulatory leptin action involves several neuronal populations and likely acts differentially on these distinct neuronal populations.

\section{LepRb neurons are synaptically coupled with rRPa neurons}

To further demonstrate that LepRb neurons indeed innervate neurons in the rRPa, we used $L e p R b^{E G P F}$ mice to identify LepRb projections into the rRPa. To visualize rRPa neurons, we counterstained with the neuronal marker NeuN. As seen in Figure 10B, we found clear LepRb projections intermingling with rRPa neurons $(n=10)$.

We further used $L e p R b^{W G A}$ mice, which have been described previously as a new tool to study synaptic targets of LepRb neurons (Leshan et al., 2010). In these mice, WGA is produced in LepRb neurons, which is known to be transported anterogradely along the axon and further transsynaptically into second-order neurons. Consistent with the identified LepRb projections in the rRPa (Figs. 7D, 10B), we were able to find WGA-labeled neurons in the $\mathrm{rRPa}$ (Fig. 10D, $n=5$ ), demonstrating that LepRb neurons indeed are synaptically coupled with rRPa neurons.

Although in these studies we cannot discriminate from which LepRb population these projections originate, we showed additionally that FG tracing from the $\mathrm{rRPa}$ intensely labels LepRb neurons in the DMH/DHA and mPOA (Fig. 8). Therefore, together these data strongly indicate that LepRb neurons in the $\mathrm{DMH} / \mathrm{DHA}$ and mPOA innervate rRPa neurons and thus might contribute importantly to the regulation of rRPa neurons.

\section{A population of LepRb neurons in the $\mathrm{mPOA}$ projects to the DMH/DHA}

Neurons in the mPOA are required for maintenance of basal body temperature, as well as cold or lipopolysaccharide (LPS) induced fever response (Yoshida et al., 2009). These mPOA neurons project directly to the $\mathrm{rRPa}$ ( $\mathrm{mPOA}>\mathrm{rRPa}$ neurons) but 


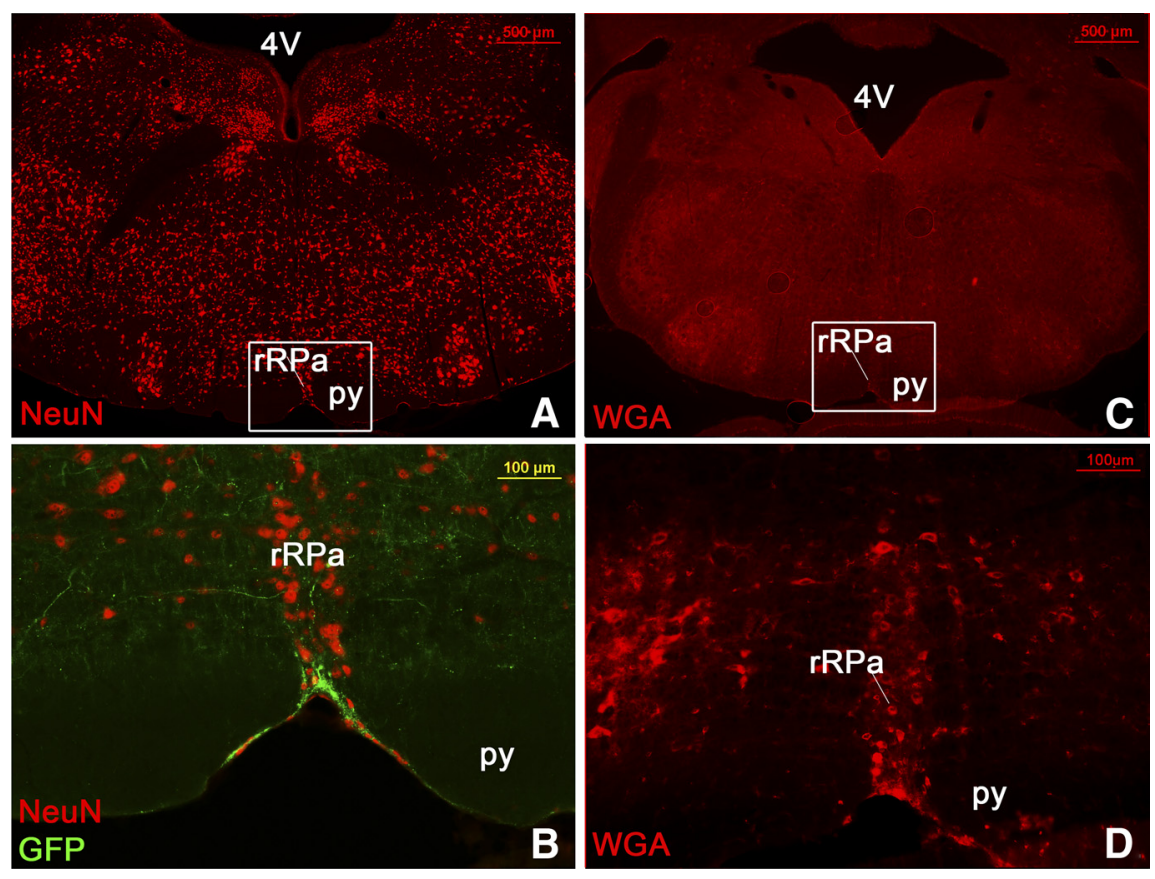

Figure 10. LepRb neurons are synaptically coupled with neurons in the rRPa. In LepRb ${ }^{E G F P}$ reporter mice, LepRb ${ }^{\text {EGFP }}$-positive fibers (green) are seen in close proximity to neurons in the $\mathrm{rRPa}(\mathrm{red})(\boldsymbol{B}, n=10)$. The same section is shown as an overview with NeuN stain in $\boldsymbol{A}$. Transsynaptically labeled WGA-positive neurons are found in the rRPa of $L e p R b^{W G A}$ mice $(\boldsymbol{D}, n=5)$, indicating synaptic coupling of LepRb neurons with rRPa neurons. An overview of the same sections is shown in C. 4V, Fourth ventricle; py, pyramidal tract.

also to the DMH/DHA (mPOA $>$ DMH/DHA neurons) (Nakamura et al., 2005; Yoshida et al., 2009). Importantly, a functional $\mathrm{DMH}$ is required to mediate $\mathrm{mPOA}$-evoked thermoregulatory responses (Dimicco and Zaretsky, 2007), further supporting the relevance of $\mathrm{mPOA}>\mathrm{DMH} / \mathrm{DHA}$ projections

Thus, we hypothesized that LepRb neurons would be also present on $\mathrm{mPOA}>\mathrm{DMH} / \mathrm{DHA}$ neurons and analyzed colocalization of mPOA LepRb with FG-labeled neurons from the DMH/ DHA (Fig. 11A,B). Indeed, we found several mPOA neurons retrogradely labeled with FG from the DMH/DHA, and many LepRb neurons in the mPOA (including the MnPO and MPA) were colocalized with FG (Fig. 11C,D), demonstrating that they project into the DMH/DHA. Therefore, these data suggest that DMH/DHA and $\mathrm{mPOA}$ LepRb neurons represent both inputs to premotor $\mathrm{rRPa}$ neurons and that $\mathrm{mPOA}>\mathrm{DMH} / \mathrm{DHA}$ LepRb neurons directly interact with LepRb neurons in the DMH/DHA as schematically summarized in Figure 12, suggesting a crosstalk of different LepRb populations in thermoregulatory control.

\section{Discussion}

It is well established that leptin-deficient mice are hypothermic $\left(\sim 1^{\circ} \mathrm{C}\right.$ vs wild-type mice) and are unable to defend their body temperature during acute cold exposure (Trayhurn et al., 1976, 1977). The thermoregulatory defects in these mice have been attributed to defective BAT thermogenesis (Goodbody and Trayhurn, 1982; Himms-Hagen, 1985), but little is known about the neuronal circuits involved.

In the thermogenic field, several discoveries over the last years have led to the identification of important neuronal circuits, including the $\mathrm{mPOA}$ and $\mathrm{DMH} / \mathrm{DHA}$, and their interaction with the $\mathrm{rRPa}$ (Dimicco and Zaretsky, 2007; Morrison et al., 2008), a key component in the thermoregulatory adaptation to cold exposure and febrile responses to endotoxins (Nakamura et al., 2005, 2009).
LepRb neurons represent thermoregulatory circuits in the DMH/ DHA and $\mathrm{mPOA}$

In this study, we show anatomical evidence that LepRb neurons in the DMH/DHA and mPOA contributed to the regulation of sympathetic BAT outputs. We identified LepRb in the DMH/DHA and mPOA that were labeled with PRV from the exclusively sympathetic innervated BAT. We further demonstrated that LepRb neurons are synaptically coupled with $\mathrm{rRPa}$ neurons and that specifically $\mathrm{DMH} / \mathrm{DHA}$ LepRb neurons project to the $\mathrm{rRPa}$ and are stimulated during acute cold exposure. This strongly suggests that LepRb neurons in the DMH/DHA represent thermoregulatory neurons that play a key role in the regulation of BAT thermogenesis as described by Nakamura et al. (2005, 2009).

Furthermore, we found that LepRb neurons in the mPOA project to the $\mathrm{DMH} / \mathrm{DHA}$ and $\mathrm{rRPa}$, consistent with studies in the rat (Nakamura et al., 2005, 2009; Dimicco and Zaretsky, 2007; Yoshida et al., 2009). Thus, leptin action appears to interact on several levels within this thermoregulatory circuit, showing parallel inputs to the $\mathrm{rRPa}$ from the mPOA and DMH/DHA and suggesting an interaction of LepRb populations in the $\mathrm{mPOA}$ and $\mathrm{DMH} / \mathrm{DHA}$.

Leptin targets in thermoregulatory control beyond the DMH/ DHA and mPOA

We also found LepRb neurons in the RCh, NTS, and EW consistently labeled with PRV from the BAT. Whereas the neuronal circuits of these sites, particularly with regard to thermoregulation, have not been investigated in detail, some data support their involvement in thermoregulatory control.

The RCh lays rostral to the ARC and harbors a large population of proopiomelancortin (POMC)-expressing neurons, which are predominantly colocalized with LepRb in the RCh and rostral ARC (Münzberg et al., 2003). POMC cleavage products stimulate melanocortin 3 and 4 receptors and have been long known to induce thermogenesis along with their important anorexigenic effects (Raible and Knickerbocker, 1993; Sinha et al., 2004; Fan et al., 2005).

The NTS is the major input structure for vagal afferents. NTS neurons are known to project locally within the brainstem but also to hypothalamic structures (e.g., the DMH and PVN) that have been shown to regulate sympathetic outputs to the BAT (Geerling and Loewy, 2006). Although leptin alone is unable to regulate BAT thermogenesis via the brainstem, a gating role has been proposed for leptin in combination with thyroid releasing hormone (TRH), which elicited a large increase in body temperature $\left(3.5^{\circ} \mathrm{C}\right)$ during leptin pretreatment compared with a $1^{\circ} \mathrm{C}$ increase by TRH alone (Hermann et al., 2006; Mark et al., 2009; Rogers et al., 2009).

The EW is a midbrain structure that can be divided into cholinergic preganglionic neurons involved in oculomotor functions and urocortin-1 expressing non-preganglionic neurons (npEW) 

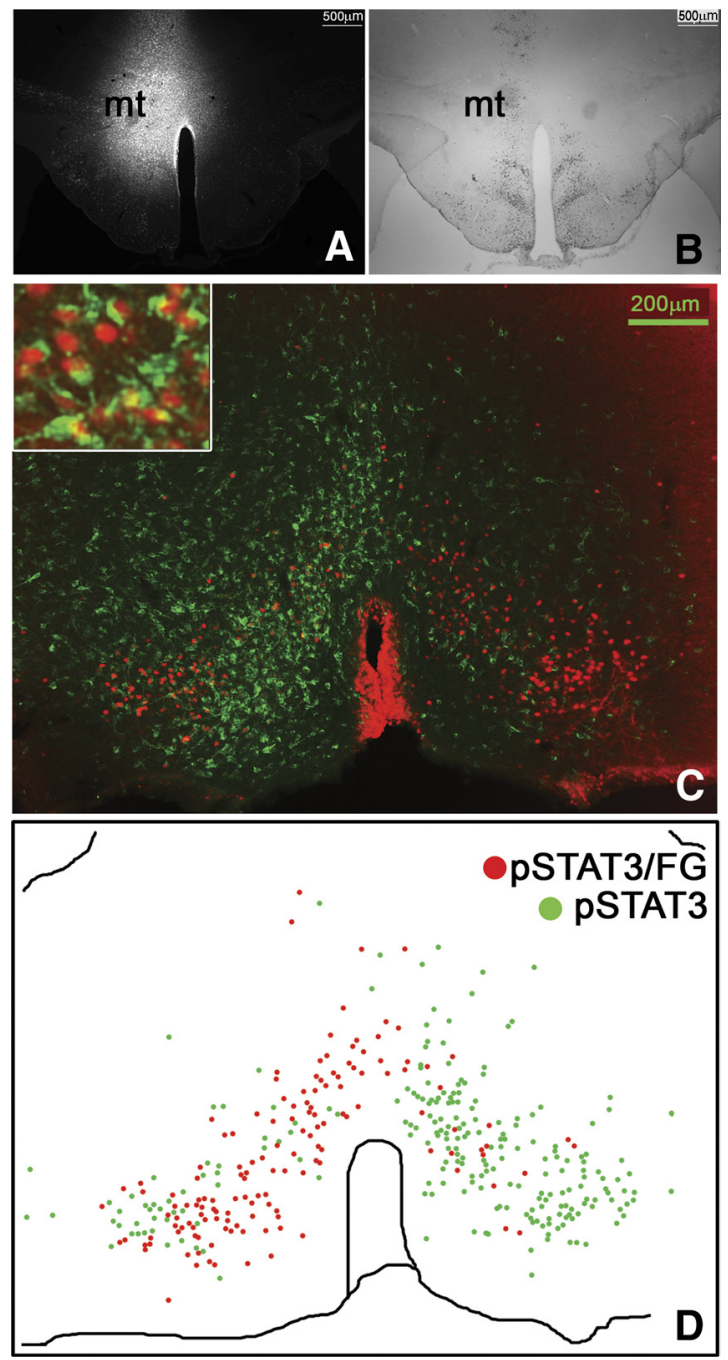

Figure 11. Stereotaxic injection of the retrograde tracer $\mathrm{FG}$ into the $\mathrm{DMH} / \mathrm{DHA}(\boldsymbol{A}, n=3)$ and IHC for leptin-induced pSTAT3 $(\boldsymbol{B})$ to demonstrate the location of the FG injection relative to LepRb neurons in the DMH/DHA. Immunohistochemical detection of retrogradely labeled FG (green) in LepRb neurons (leptin-induced pSTAT3, red) in the mPOA $(\boldsymbol{C})$ and schematic drawing of double-labeled FG/pSTAT3 neurons (red dots) in contrast to non-FG-labeled pSTAT3 neurons (green dots) in the MPOA (D).

that are involved in stress and anxiety (Kozicz, 2007). LepRb neurons in the EW have been found to colocalize with anorexigenic urocortin, showing that LepRb neurons are part of the npEW (Xu et al., 2009). The npEW has not been associated with thermoregulation in particular, but stress-induced hyperther$\mathrm{mia} /$ fever is well documented and might involve the npEW (Bouwknecht and Paylor, 2002).

Thus, additional investigations will be necessary to specify the thermoregulatory role of RCh, NTS, and EW as well as the importance of leptin action in these sites.

\section{Leptin action in thermoregulation}

Fever

A coordinated rise in body temperature attributable to inflammation, infection, or stress is commonly described as fever and causes vasoconstriction and BAT thermogenesis to raise body temperature (Székely and Szelényi, 1979). Bacterial LPS have been used experimentally to induce fever, and cytokines, such as interleukins (IL-1 $\beta$, IL-6), tumor necrosis factor (TNF $\alpha$ ) and prostaglandins (PG), are involved to mediate LPS-induced fever (Kluger et al., 1995; Luheshi and Rothwell, 1996).

An involvement of leptin in febrile responses has been discussed controversially. Leptin gene expression and serum leptin levels are induced by LPS, IL- $1 \beta$, IL-6, TNF $\alpha$, or PG, and, consistent with other studies, leptin receptor deficiency has been found to be associated with a suppressed fever response to LPS (Dascombe et al., 1989; Busbridge et al., 1990; Rosenthal et al., 1996; Plata-Salamán et al., 1998; Ivanov and Romanovsky, 2002). In contrast, leptin-receptor-deficient rats housed at thermoneutral temperature have normal febrile responses (Ivanov and Romanovsky, 2002). LPS-induced fever is essentially independent of BAT thermogenesis under thermoneutral conditions rather than using skin vasoconstriction to decrease heat loss and thus increase body temperature (Székely and Szelényi, 1979), which might explain this controversy.

Our findings provide a neuroanatomical basis to support a role of leptin action in fever responses. Interestingly, recent findings suggest that specific thermoregulatory systems that regulate fever or basal body temperature involve distinct as well as overlapping neuronal populations in the mPOA (Yoshida et al., 2009). The involvement of leptin action in several of these thermoregulatory circuits as well as other sites, with potentially counteracting functions in the MPOA and DMH/DHA, might further account for some of the controversy of febrile leptin action. The identification of LepRb neurons in known thermoregulatory circuits, however, will help to further dissect the role of leptin in these circuits under specific thermoregulatory conditions.

\section{Cold-induced thermogenesis}

Leptin-deficient mice are unable to adapt to acute cold exposure, whereas exogenous leptin replacement rapidly rescues their ability to survive the cold (Trayhurn et al., 1976; Ukropec et al., 2006). In addition, their BAT capacity is severely decreased and UCP1 transcripts are not induced in response to cold (HimmsHagen, 1985). However, the mechanisms of leptin action on thermoregulation are not well understood.

Animals with decreased leptin levels attributable to body fat loss during prolonged fasting or food restriction (as well as obese but leptin-deficient mice) perform daily torpor with a substantial decrease in body temperature to preserve body reserves. Exogenous leptin injections prevent these torpor events (Gavrilova et al., 1999), possibly by increasing UCP1 expression in response to leptin (Scarpace et al., 1997; Commins et al., 1999), which would involve an increased sympathetic tone to the BAT. Therefore, this suggests that leptin would have a stimulatory effect on DMH/DHA neurons.

In contrast, in humans, daily fluctuations of body temperature underlying the sleep-wake cycles is associated with high circulating leptin levels during sleep cycles and thus low body temperature (Simon et al., 1998). In addition, cold exposure generally decreases leptin mRNA expression in adipose tissue (Evans et al., 1999), supporting an inhibitory action of leptin on DMH/DHA neurons.

Furthermore, although leptin-deficient mice can die from hypothermia by acute cold exposure $\left(4^{\circ} \mathrm{C}\right)$, they are capable of adjusting to the same cold environment by gradual adaptation to the cold (reduction of temperature by $2-3^{\circ} \mathrm{C} / \mathrm{d}$ ), which involves a UCP1-independent mechanism that requires TRH and leptin for proper function (Ukropec et al., 2006).

Therefore, complex interactions of diverse systems collectively regulate body temperature, and leptin appears to plays a key role in orchestrating these diverse systems. Additional studies will be necessary to investigate the effects of leptin on DMH/DHA and $\mathrm{mPOA}$ neurons in specific thermoregulatory situations. 


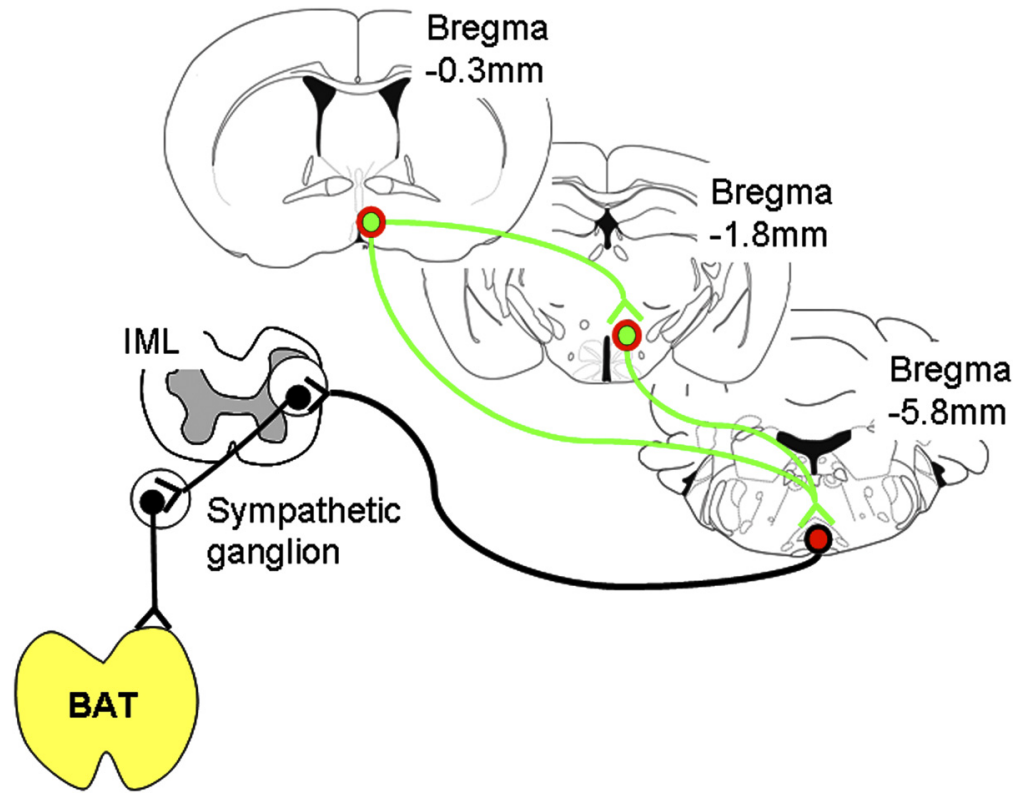

Figure 12. Schematic drawing of identified LepRb connections involved in thermoregulatory circuits.

interscapular adipose tissue during cold exposure. J Comp Neurol 460:303-326.

Commins SP, Watson PM, Padgett MA, Dudley A, Argyropoulos G, Gettys TW (1999) Induction of uncoupling protein expression in brown and white adipose tissue by leptin. Endocrinology 140:292-300.

Dascombe MJ, Hardwick A, Lefeuvre RA, Rothwell NJ (1989) Impaired effects of interleukin-1 beta on fever and thermogenesis in genetically obese rats. Int J Obes 13:367-373.

Dhillon H, Zigman JM, Ye C, Lee CE, McGovern RA, Tang V, Kenny CD, Christiansen LM, White RD, Edelstein EA, Coppari R, Balthasar N, Cowley MA, Chua S Jr, Elmquist JK, Lowell BB (2006) Leptin directly activates SF1 neurons in the $\mathrm{VMH}$, and this action by leptin is required for normal body-weight homeostasis. Neuron 49:191-203.

Dimicco JA, Zaretsky DV (2007) The dorsomedial hypothalamus: a new player in thermoregulation. Am J Physiol Regul Integr Comp Physiol 292:R47-R63.

Elmquist JK, Scammell TE, Jacobson CD, Saper CB (1996) Distribution of Fos-like immunoreactivity in the rat brain following intravenous lipopolysaccharide administration. J Comp Neurol 371:85-103.

\section{Thermoregulation and body weight}

A role of BAT function in the development of obesity has been speculated, although the presence and functionality of BAT in adult humans has been doubted. However, recent studies clearly demonstrated the presence of large amounts of functional BAT in adult humans and revived the interest in thermogenic BAT function, their underlying neuronal circuits, and their endogenous regulators as potential targets for obesity drugs (Garrow, 1983; Frühbeck et al., 2009).

It has been long known that the ingestion of high caloric food is associated with an increase in body temperature, sympathetic tone, and BAT capacity (Rothwell and Stock, 1979). However, if these effects indeed involve controlled adaptive thermogenesis (via centrally controlled BAT thermogenesis) or if simply thermic effects are involved (attributable to increased digestive function and metabolizing additional fuels) has not been resolved (Garrow, 1983; Nedergaard et al., 2007; Ravussin and Kozak, 2009).

Our data support the possibility that the action of leptin on energy homeostasis uses several thermoregulatory circuits, and additional studies are necessary to specifically address the importance of thermoregulatory control by leptin for whole-body energy balance and the development of obesity.

\section{References}

Ahima RS, Saper CB, Flier JS, Elmquist JK (2000) Leptin regulation of neuroendocrine systems. Front Neuroendocrinol 21:263-307.

Bailey TW, Dimicco JA (2001) Chemical stimulation of the dorsomedial hypothalamus elevates plasma ACTH in conscious rats. Am J Physiol Regul Integr Comp Physiol 280:R8-R15.

Bamshad M, Song CK, Bartness TJ (1999) CNS origins of the sympathetic nervous system outflow to brown adipose tissue. Am J Physiol 276:R1569-R1578.

Banfield BW, Kaufman JD, Randall JA, Pickard GE (2003) Development of pseudorabies virus strains expressing red fluorescent proteins: new tools for multisynaptic labeling applications. J Virol 77:10106-10112.

Bouwknecht JA, Paylor R (2002) Behavioral and physiological mouse assays for anxiety: a survey in nine mouse strains. Behav Brain Res 136:489-501.

Busbridge NJ, Carnie JA, Dascombe MJ, Johnston JA, Rothwell NJ (1990) Adrenalectomy reverses the impaired pyrogenic responses to interleukin-beta in obese Zucker rats. Int J Obes 14:809-814.

Cano G, Passerin AM, Schiltz JC, Card JP, Morrison SF, Sved AF (2003) Anatomical substrates for the central control of sympathetic outflow to
Evans BA, Agar L, Summers RJ (1999) The role of the sympathetic nervous system in the regulation of leptin synthesis in C57BL/6 mice. FEBS Lett 444:149-154.

Fan W, Voss-Andreae A, Cao WH, Morrison SF (2005) Regulation of thermogenesis by the central melanocortin system. Peptides 26:1800-1813.

Faouzi M, Leshan R, Björnholm M, Hennessey T, Jones J, Münzberg H (2007) Differential accessibility of circulating leptin to individual hypothalamic sites. Endocrinology 148:5414-5423.

Frühbeck G, Becerril S, Sáinz N, Garrastachu P, García-Velloso MJ (2009) BAT: a new target for human obesity? Trends Pharmacol Sci 30:387-396.

Garrow JS (1983) Luxuskonsumption, brown fat, and human obesity. $\mathrm{Br}$ Med J (Clin Res Ed) 286:1684-1686.

Gavrilova O, Leon LR, Marcus-Samuels B, Mason MM, Castle AL, Refetoff S, Vinson C, Reitman ML (1999) Torpor in mice is induced by both leptindependent and -independent mechanisms. Proc Natl Acad Sci U S A 96:14623-14628.

Geerling JC, Loewy AD (2006) Aldosterone-sensitive neurons in the nucleus of the solitary: efferent projections. J Comp Neurol 498:223-250.

Goodbody AE, Trayhurn P (1982) Studies on the activity of brown adipose tissue in suckling, pre-obese, ob/ob mice. Biochim Biophys Acta 680:119-126.

Hausberg M, Morgan DA, Mitchell JL, Sivitz WI, Mark AL, Haynes WG (2002) Leptin potentiates thermogenic sympathetic responses to hypothermia: a receptor-mediated effect. Diabetes 51:2434-2440.

Hermann DM, Luppi PH, Peyron C, Hinckel P, Jouvet M (1997) Afferent projections to the rat nuclei raphe magnus, raphe pallidus and reticularis gigantocellularis pars alpha demonstrated by iontophoretic application of choleratoxin (subunit b). J Chem Neuroanat 13:1-21.

Hermann GE, Barnes MJ, Rogers RC (2006) Leptin and thyrotropinreleasing hormone: cooperative action in the hindbrain to activate brown adipose thermogenesis. Brain Res 1117:118-124.

Himms-Hagen J (1985) Defective brown adipose tissue thermogenesis in obese mice. Int J Obes 9 [Suppl 2]:17-24.

Hosoi T, Kawagishi T, Okuma Y, Tanaka J, Nomura Y (2002) Brain stem is a direct target for leptin's action in the central nervous system. Endocrinology 143:3498-3504.

Hosoya Y, Ito R, Kohno K (1987) The topographical organization of neurons in the dorsal hypothalamic area that project to the spinal cord or to the nucleus raphe pallidus in the rat. Exp Brain Res 66:500-506.

Hosoya Y, Sugiura Y, Zhang FZ, Ito R, Kohno K (1989) Direct projection from the dorsal hypothalamic area to the nucleus raphe pallidus: a study using anterograde transport with Phaseolus vulgaris leucoagglutinin in the rat. Exp Brain Res 75:40-46.

Hunt JL, Zaretsky DV, Sarkar S, Dimicco JA (2010) Dorsomedial hypothalamus mediates autonomic, neuroendocrine, and locomotor responses 
evoked from the medial preoptic area. Am J Physiol Regul Integr Comp Physiol 298:R130-R140.

Ivanov AI, Romanovsky AA (2002) Fever responses of Zucker rats with and without fatty mutation of the leptin receptor. Am J Physiol Regul Integr Comp Physiol 282:R311-R316.

Kerman IA, Akil H, Watson SJ (2006) Rostral elements of sympatho-motor circuitry: a virally mediated transsynaptic tracing study. J Neurosci 26:3423-3433.

Kluger MJ, Kozak W, Leon LR, Soszynski D, Conn CA (1995) Cytokines and fever. Neuroimmunomodulation 2:216-223.

Kozicz T (2007) On the role of urocortin 1 in the non-preganglionic Edinger-Westphal nucleus in stress adaptation. Gen Comp Endocrinol 153:235-240.

Leinninger GM, Jo YH, Leshan RL, Louis GW, Yang H, Barrera JG, Wilson H, Opland DM, Faouzi MA, Gong Y, Jones JC, Rhodes CJ, Chua S Jr, Diano S, Horvath TL, Seeley RJ, Becker JB, Münzberg H, Myers MG Jr (2009) Leptin acts via leptin receptor-expressing lateral hypothalamic neurons to modulate the mesolimbic dopamine system and suppress feeding. Cell Metab 10:89-98.

Leshan RL, Björnholm M, Münzberg H, Myers MG Jr (2006) Leptin receptor signaling and action in the central nervous system. Obesity (Silver Spring) 14 [Suppl 5]:208S-212S.

Leshan RL, Louis GW, Jo YH, Rhodes CJ, Münzberg H, Myers MG Jr (2009) Direct innervation of GnRH neurons by metabolic- and sexual odorantsensing leptin receptor neurons in the hypothalamic ventral premammillary nucleus. J Neurosci 29:3138-3147.

Leshan RL, Opland DM, Louis GW, Leinninger GM, Patterson CM, Rhodes CJ, Münzberg H, Myers MG Jr (2010) Ventral tegmental area leptin receptor neurons specifically project to and regulate cocaine- and amphetamine-regulated transcript neurons of the extended central amygdala. J Neurosci 30:5713-5723.

Luheshi G, Rothwell N (1996) Cytokines and fever. Int Arch Allergy Immunol 109:301-307.

Mark AL, Agassandian K, Morgan DA, Liu X, Cassell MD, Rahmouni K (2009) Leptin signaling in the nucleus tractus solitarii increases sympathetic nerve activity to the kidney. Hypertension 53:375-380.

Morrison SF, Nakamura K, Madden CJ (2008) Central control of thermogenesis in mammals. Exp Physiol 93:773-797.

Münzberg H, Huo L, Nillni EA, Hollenberg AN, Bjørbaek C (2003) Role of signal transducer and activator of transcription 3 in regulation of hypothalamic proopiomelanocortin gene expression by leptin. Endocrinology 144:2121-2131.

Münzberg H, Jobst EE, Bates SH, Jones J, Villanueva E, Leshan R, Björnholm M, Elmquist J, Sleeman M, Cowley MA, Myers MG Jr (2007) Appropriate inhibition of orexigenic hypothalamic arcuate nucleus neurons independently of leptin receptor/STAT3 signaling. J Neurosci 27:69-74.

Myers MG Jr, Münzberg H, Leinninger GM, Leshan RL (2009) The geometry of leptin action in the brain: more complicated than a simple ARC. Cell Metab 9:117-123.

Nakamura K, Matsumura K, Hübschle T, Nakamura Y, Hioki H, Fujiyama F, Boldogköi Z, König M, Thiel HJ, Gerstberger R, Kobayashi S, Kaneko T (2004) Identification of sympathetic premotor neurons in medullary raphe regions mediating fever and other thermoregulatory functions. J Neurosci 24:5370-5380.

Nakamura Y, Nakamura K, Matsumura K, Kobayashi S, Kaneko T, Morrison SF (2005) Direct pyrogenic input from prostaglandin EP3 receptorexpressing preoptic neurons to the dorsomedial hypothalamus. Eur J Neurosci 22:3137-3146.

Nakamura Y, Nakamura K, Morrison SF (2009) Different populations of prostaglandin EP3 receptor-expressing preoptic neurons project to two fever-mediating sympathoexcitatory brain regions. Neuroscience 161:614-620

Nedergaard J, Bengtsson T, Cannon B (2007) Unexpected evidence for active brown adipose tissue in adult humans. Am J Physiol Endocrinol Metab 293:E444-E452.

Ozata M, Ozdemir IC, Licinio J (1999) Human leptin deficiency caused by a missense mutation: multiple endocrine defects, decreased sympathetic tone, and immune system dysfunction indicate new targets for leptin action, greater central than peripheral resistance to the effects of leptin, and spontaneous correction of leptin-mediated defects. J Clin Endocrinol Metab 84:3686-3695.
Paxinos G, Franklin KB (2004) The mouse brain in stereotaxic coordinates. San Diego: Elsevier Science.

Paxinos G, Watson C (1998) The rat brain in stereotaxic coordinates. San Diego: Academic.

Plata-Salamán CR, Peloso E, SatinoffE (1998) Cytokine-induced fever in obese (fa/fa) and lean $(\mathrm{Fa} / \mathrm{Fa})$ Zucker rats. Am J Physiol 275:R1353-R1357.

Raible LH, Knickerbocker D (1993) Alpha-melanocyte-stimulating hormone (MSH) and [Nle4,D-Phe7]-alpha-MSH: effects on core temperature in rats. Pharmacol Biochem Behav 44:533-538.

Ravussin E, Kozak LP (2009) Have we entered the brown adipose tissue renaissance? Obes Rev 10:265-268.

Rogers RC, Barnes MJ, Hermann GE (2009) Leptin "gates” thermogenic action of thyrotropin-releasing hormone in the hindbrain. Brain Res 1295:135-141.

Rosenthal M, Roth J, Störr B, Zeisberger E (1996) Fever response in lean $(\mathrm{Fa} /-)$ and obese (fa/fa) Zucker rats and its lack to repeated injections of LPS. Physiol Behav 59:787-793.

Rothwell NJ, Stock MJ (1979) A role for brown adipose tissue in dietinduced thermogenesis. Nature 281:31-35.

Rummel C, Voss T, Matsumura K, Korte S, Gerstberger R, Roth J, Hübschle T (2005) Nuclear STAT3 translocation in guinea pig and rat brain endothelium during systemic challenge with lipopolysaccharide and interleukin-6. J Comp Neurol 491:1-14.

Sarkar S, Zaretskaia MV, Zaretsky DV, Moreno M, DiMicco JA (2007) Stress- and lipopolysaccharide-induced c-fos expression and nNOS in hypothalamic neurons projecting to medullary raphe in rats: a triple immunofluorescent labeling study. Eur J Neurosci 26:2228-2238.

Scarpace PJ, Matheny M, Pollock BH, Tümer N (1997) Leptin increases uncoupling protein expression and energy expenditure. Am J Physiol 273:E226-E230.

Simon C, Gronfier C, Schlienger JL, Brandenberger G (1998) Circadian and ultradian variations of leptin in normal man under continuous enteral nutrition: relationship to sleep and body temperature. J Clin Endocrinol Metab 83:1893-1899.

Sinha PS, Schiöth HB, Tatro JB (2004) Roles of the melanocortin-4 receptor in antipyretic and hyperthermic actions of centrally administered alphaMSH. Brain Res 1001:150-158.

Székely M, Szelényi Z (1979) Endotoxin fever in the rat. Acta Physiol Acad Sci Hung 53:265-277.

ter Horst GJ, Luiten PG (1986) The projections of the dorsomedial hypothalamic nucleus in the rat. Brain Res Bull 16:231-248.

Thompson RH, Canteras NS, Swanson LW (1996) Organization of projections from the dorsomedial nucleus of the hypothalamus: a PHA-L study in the rat. J Comp Neurol 376:143-173.

Trayhurn P, Thurlby PL, James WP (1976) A defective response to cold in the obese (obob) mouse and the obese Zucker (fafa) rat [proceedings]. Proc Nutr Soc 35:133A.

Trayhurn P, Thurlby PL, James WP (1977) Thermogenic defect in preobese ob/ob mice. Nature 266:60-62.

Ukropec J, Anunciado RV, Ravussin Y, Kozak LP (2006) Leptin is required for uncoupling protein-1-independent thermogenesis during cold stress. Endocrinology 147:2468-2480.

Voss-Andreae A, Murphy JG, Ellacott KL, Stuart RC, Nillni EA, Cone RD, Fan W (2007) Role of the central melanocortin circuitry in adaptive thermogenesis of brown adipose tissue. Endocrinology 148:1550-1560.

Xu L, Bloem B, Gaszner B, Roubos EW, Kozicz T (2009) Sex-specific effects of fasting on urocortin 1, cocaine- and amphetamine-regulated transcript peptide and nesfatin-1 expression in the rat Edinger-Westphal nucleus. Neuroscience 162:1141-1149.

Yoshida K, Li X, Cano G, Lazarus M, Saper CB (2009) Parallel preoptic pathways for thermoregulation. J Neurosci 29:11954-11964.

Zaretskaia MV, Zaretsky DV, Shekhar A, DiMicco JA (2002) Chemical stimulation of the dorsomedial hypothalamus evokes non-shivering thermogenesis in anesthetized rats. Brain Res 928:113-125.

Zaretskaia MV, Zaretsky DV, DiMicco JA (2003) Role of the dorsomedial hypothalamus in thermogenesis and tachycardia caused by microinjection of prostaglandin E2 into the preoptic area in anesthetized rats. Neurosci Lett 340:1-4.

Zaretskaia MV, Zaretsky DV, Sarkar S, Shekhar A, DiMicco JA (2008) Induction of Fos-immunoreactivity in the rat brain following disinhibition of the dorsomedial hypothalamus. Brain Res 1200:39-50. 